$\mathcal{G}_{\text {https://doi.org/10.3765/sp.14.7 }}^{\text {Semantics \& Pragmatics Volume 14, Article 7: 1-54, } 2021}$

\title{
A variably exhaustive and scalar focus particle and pragmatic focus concord in Burmese*
}

\author{
Michael Yoshitaka Erlewine \\ National University of Singapore
}

\author{
Keely New \\ National University of Singapore
}

Submitted 2019-07-22 / First decision 2019-11-11 / Revision received 2021-04-05 / Second decision 2021-05-04 / Revision received 2021-05-12 / Accepted 2021-06-09 / Published 2021-06-14 / Final typesetting 2023-01-18

\begin{abstract}
The Burmese particle hmá expresses cleft-like exhaustivity in some contexts but a scalar, even-like meaning in other contexts. We propose that hmá is uniformly a not-at-issue scalar exhaustive, with semantics similar to that proposed for English it-clefts in Velleman, Beaver, Destruel, Bumford, Onea \& Coppock 2012. When hmá takes wide scope, it leads to an exhaustive interpretation which is not scale-sensitive. When hmá takes scope under negation, the resulting expression will have a scale-sensitive felicity condition due to a Non-Vacuity constraint. We show that hmá makes reference to alternatives ordered by likelihood, but cannot use other contextual orderings such as rank-orders.

We also analyze the sentence-final mood marker $t a / d a$, which frequently but not always appears in scalar hmá utterances, in a manner similar to focus concord effects in other languages. We propose that $t a / d a$ is a marker of propositional clefts and argue that the semantics of hmá and the pragmatic requirements of propositional clefts together derive this apparent focus concord effect, as well as its exceptions.
\end{abstract}

Keywords: Burmese, focus particle, exhaustivity, scalarity, Non-Vacuity, propositional cleft, focus concord / kakari-musubi

* We thank our Burmese speakers and teachers, Kaung Mon Thu, Phyo Thi Han, Phyo Thura Htay, Chit Thiri Maung, Saw Ohnmar Oo, Nyan Lin Htoo, Yukei Oo, and Cho Cho Mar Aung for sharing their language with us. We also thank Chris Davis, Hadas Kotek, and Elin McCready, the audience at SALT 28, and our $S \& P$ reviewers and editor Judith Tonhauser for helpful comments and discussion. We thank Meghan Lim for assistance in verifying our transcriptions. The first author led the analysis and writing and the second author led all data collection. This research is supported by the Singapore Ministry of Education Academic Research Fund through MOE2017-T2-2-094, which is gratefully acknowledged.

(C2021 Michael Yoshitaka Erlewine and Keely New

This is an open-access article distributed under the terms of a Creative Commons Attribution License (https://creativecommons.org/licenses/by/3.o/). 
Erlewine, New

\section{Introduction}

This paper investigates the Colloquial Burmese focus particle hmá $\varrho$, which descriptively contributes exhaustivity in some contexts and a scalar meaning in others. The affirmative declarative sentence with hmá in (1) has an exhaustive interpretation. The negative declarative sentence with hmá in (2) has a scalar interpretation, similar to what is conveyed by English not...even. ${ }^{1}$

(1) Exhaustive hmá (cleft-like):

Aun=gá $\quad$ ye=go=hmá thauq-k'éh-deh.

Aung $=$ NOM water $=$ ACC $=$ HMÁ drink-PST-NFUT

$\approx$ 'It's WATER that Aung drank.'

(2) Scalar hmá ('even’-like):

Aun=gá $\quad$ ye=go=hmá mă-thauq-k'éh-da.

Aung $=$ NOM water $=$ ACC $=$ HMÁ NEG-drink-PST-DA

₹ 'Aung didn't even drink WATER.'

In his reference grammar of Colloquial Burmese, Okell (1969: pp. 284-286) includes two separate lexical entries for " $h m a_{\mathrm{A}}$ " and " $h m a_{\mathrm{B}}$ ", respectively translated as 'only' and 'even' and corresponding to the uses in (1) and (2), with no description of the distributions of these two uses. Burmese also has distinct particles for 'only' p'èh/bèh and 'even' taun/daun, both of which differ in behavior from $h m a ́$, as we shall see.

In this paper we propose a uniform semantics for hmá. After some background on the Burmese verbal complex in Section 2, we begin in Section 3 by describing the environments associated with $h m a ́$ 's exhaustive and scalar uses. We propose in Section 4 that hmá is a not-at-issue scalar exhaustive with semantics similar to that proposed for English it-clefts in Velleman,

An earlier version of this work appeared in the Proceedings of SALT 28 as New \& Erlewine 2018. The core data and analytic insights overlap, but the present paper expands and clarifies the empirical description and further develops the analysis of the role of sentence-final $t a / d a$ in Section 6, also better relating the phenomena here to work on similar particles, propositional clefts, and focus concord in other languages, as well as to other focus particles in Burmese.

1 We follow the transcription conventions for Burmese employed in Okell 1994, 2002; notably, $\breve{a}$ is a schwa and the coda $q$ is a glottal stop. Burmese has a process of word- and phraseinternal intervocalic voicing, which for example results in the case markers ká and ko voicing to gá and go in many positions. Except where noted, all abbreviations in glosses follow the Leipzig glossing conventions. The mood marker TA/DA will be discussed in Section 6 . 
A variably exhaustive and scalar focus particle in Burmese

Beaver, Destruel, Bumford, Onea \& Coppock 2012, and in Section 5 we discuss similar particles which have been attested cross-linguistically, for which our analysis may also plausibly apply.

We then discuss the semantics of the sentence-final mood marker $t a / d a$, which commonly co-occurs with scalar uses of hmá - as in (2) above - but less often with exhaustive uses of hmá, in Section 6. This apparent correlation appears similar to so-called "focus concord" effects in other languages, which many scholars have analyzed as an agreement-like morphosyntactic dependency between verbal heads and focus particles (see e.g., Hagstrom 1998, Ikawa 1998, Watanabe 2002, Kishimoto 2005, 2018, Aldridge 2018). In contrast, we propose that this apparent correlation in Burmese is best explained as an interaction between the semantics of hmá and the independent pragmatic requirements of $t a / d a$. We identify sentence-final $t a / d a$ as a marker of propositional clefts, marking the utterance as having a particular status in the organization of the discourse, following Sheil 2016. We show how this proposal explains the frequent correlation between the interpretation of hmá and the presence or absence of $t a / d a$, as well as its exceptions. We conclude in Section 7.

The data in this paper were collected between 2017 and 2021 from extended primary fieldwork with five native speakers who now primarily reside in Singapore. The consultants are between 24 to 29 years of age, and grew up in Yangon before moving to attend English medium schools in Singapore. Multiple elicitation sessions were held with each of these speakers separately, in person, with each session typically lasting 1-1.5 hours. Except where we note explicitly, the data reported here reflect the judgments of all five of these speakers, and which were consistent across multiple sessions. In addition, we had the opportunity to verify some data points with two other speakers (in their 30's and 6o's), but were unable to meet with them further to verify the full set of judgments reported here.

All data we present below, which are used to motivate our analysis, are the results of requests for judgments of grammaticality or judgments of truth or felicity in context. Contexts were presented in English, with some informal questions used to confirm their comprehension; see Matthewson 2004 for discussion of the use of a meta-language (English) for such purposes. In many cases, speakers volunteered comments about our target utterances which also informed our analysis. To facilitate comparison across examples, we will generally present one set of supporting examples and contexts for all of the 
key claims, although variants of these examples were also tested, involving different contexts and lexical choices.

\section{Background: The Burmese verbal complex}

In this section, we give a brief introduction to features of the Burmese verbal complex that will be relevant for our discussion. Burmese is a Tibeto-Burman language spoken in Myanmar, with default SOV word order. The basic verbal complex template in Burmese is given in (3). In particular, we will see in subsequent sections that the choice of sentence-final mood marker will be relevant for describing the distribution of different uses of hmá.

\section{(3) Verbal complex template:}

$$
\text { (negation) - verb stem - (tense/aspect })-\operatorname{mood}
$$

In an affirmative declarative sentence, the verb stem combines with a post-verbal tense/aspect marker, if any, and a sentence-final mood marker. The regular mood markers are the non-future teh/deh and future meh, illustrated in (4) below. ${ }^{2}$ The use of a mood marker is obligatory.

\section{(4) The basic mood morphemes teh/deh and meh:}
a. Aun=gá ye=go thauq-k'éh-*(deh).
Aung $=$ NOM water $=$ ACC drink-PST-NFUT
'Aung drank water.'
b. Aun=gá ye=go thauq-*(meh).
Aung $=$ NOM water $=$ ACC drink-FUT
'Aung will drink water.'

Note that the surface form of the non-future marker varies between teh and deh, based on a process of word- and phrase-internal intervocalic voicing. We refer to the marker as teh/deh in prose, and similarly for other affixes which vary in this way.

Negation in a declarative sentence is expressed by the pre-verbal morpheme mă coupled with the sentence-final negative mood marker $p$ 'ù/bù. The negative mood marker $p$ 'ù/bù takes the place of the final mood markers

2 We follow Jenny \& Hnin Tun 2016 in glossing these as non-future vs future, but we note that many other scholars (e.g., Romeo 2008, Soe 1999, Watkins 2005) describe these markers as realis vs irrealis. 
A variably exhaustive and scalar focus particle in Burmese

teh/deh/meh, obscuring the non-future/future distinction. (5a) is, however, understood as a past description due to the $k$ 'éh/géh morpheme. ${ }^{3}$

\section{(5) Sentential negation mă triggers $p^{\prime}$ ù/bù mood marker:}

a. Aun=gá ye=go mă-thauq-k’éh-\{bù/*deh\}.

Aung $=$ NOM water $=$ ACC NEG-drink-PST-NEG

'Aung didn't drink water.'

b. Aun=gá ye=go mă-thauq-\{bù/"meh\}.

Aung $=$ NOM water $=$ ACC NEG-drink-NEG

'Aung will not/does not drink water.'

There is one more mood marker, $t a / d a$, which will become important in our discussion below. See for example (2) above. Ta/da can appear with both affirmative and negative verbs, overriding the mood marker otherwise expected for the verb, such as an affirmative verb's teh/deh or meh or a negative verb's $p$ 'ù/bù. As we show in Section 6, the use of $t a / d a$ on a matrix clause verb reflects that the current utterance has a particular status within the organization of the discourse.

$\mathrm{Ta} / \mathrm{da}$ is also a nominalizing ending, used for headless relatives as in (6), which cannot end with a regular mood marker such as $t e h / d e h{ }^{4}$

\section{(6) Headless relative with $t a / d a$ :}

[RC Aun thauq-k'éh-\{da/*deh\}] = gá c’o-deh. Aung drink-PST- $\left\{\mathrm{DA} /{ }^{*} \mathrm{NFUT}\right\}=$ NOM sweet-NFUT

'The one that Aung drank is sweet.'

3 We gloss k'éh/géh as a past tense marker (PST), as past time reference is "the meaning that most native speakers associate” with it (Okell \& Allott 2001: p. 25); see also Okell 1969: p. 276. The morpheme also has other, spacial directional uses, with Romeo (2008: p. 57), among others, noting that "from its original function as a marker of displacement in space, it has come to be used by native speakers as a marker of displacement in time". All instances of k'éh/géh in examples here are used to indicate past time reference.

4 Headed relatives end in a regular mood marker such as teh/deh, with the addition of creaky tone, glossed here in (i) as ATTR for “attributive”, which is Okell's term.

(i) [RC Aun thauq-k'éh-déh] ye=gá c'o-deh.

Aung drink-PST-NFUT.ATTR water=NOM sweet-NFUT

'The water that Aung drank is sweet.'

Okell (1969: p. 416) suggests that the ending ta/da as in (6) likely derived historically from this mood marker with creaky tone téh/déh combined with the noun ha 'thing', as also noted by a reviewer. 
As discussed in Simpson 2008, both Colloquial Burmese (studied here) and Literary Burmese include a number of verbal endings associated with nominalizations, which have also acquired uses as verbal endings for particular types of matrix clauses. This is an instance of a pattern of historical grammaticalization that is well-attested across Tibeto-Burman languages; see for example Yap \& Grunow-Hårsta 2010, DeLancey 2011. We return to this connection between the mood marker $t a / d a$ and its function as nominalizing morphology in Section 6.

\section{The scalar and exhaustive uses of hmá}

The particle hmá appears to give rise to different interpretations in different contexts, as reflected by its variable translations as 'only' or 'even' in Okell 1969: pp. 284-286. In this section, we give a first description of the different environments which result in these different interpretations. We will see that the scalar, 'even'-like reading is only available in clauses with local (clausemate) negation, and furthermore that this reading is often accompanied by the sentence-final mood marker $t a / d a$. The use of hmá in affirmative clauses and in many negative clauses without $\mathrm{ta} / \mathrm{da}$ have an exhaustive interpretation.

In the examples in this section, evaluated in the contexts discussed, we will see a neat correlation between the scalar and exhaustive uses of hmá with the presence or absence of the $t a / d a$ mood marker. However, we will show in Section 6 below that this correlation is not absolute, and can be dissociated in both directions.

Before we begin, some discussion is in order regarding these notions of exhaustivity and scalarity. hmá is a constituent focus particle which adjoins to a focus-containing constituent. Let $\mathrm{X}$ be the stated, prejacent value of the focused constituent, and Alt be a contextually-determined set of alternatives to $\mathrm{X}$. An exhaustive use is one which elicits an inference that the alternative propositions with $\mathrm{X}$ replaced by any alternative in Alt will be false. A scalar use is one where the felicity of the utterance with hmá depends on the ranking of $\mathrm{X}$ with respect to its alternatives in Alt, based on their associated propositions' relative likelihood. Examples with exhaustive hmá are not sensitive to this relative ranking of $X$.

Our speakers, who are bilingual in Burmese and English, translate the exhaustive uses of hmá with an English it-cleft or only and translate the 
A variably exhaustive and scalar focus particle in Burmese

scalar uses with English even. (We identify the exhaustive use as more similar to cleft semantics rather than only semantics, so we give approximate translations using English it-clefts for the exhaustive uses.) However, our description of particular uses as "exhaustive" or "scalar" is not determined by these speakers' English translations, and instead depends on our diagnostics for exhaustivity and scale-sensitivity. ${ }^{5}$ Our descriptions of hmá as "exhaustive" or "scalar" are descriptive labels which reflect the overall contribution of hmá in a particular example.

We begin with an illustration of scalar hmá. Consider (8a) and (8b) evaluated in context (7). Here we refer to the propositions of the form 'that Aung drank X' without negation as the prejacent propositions of $(8 \mathrm{a}, \mathrm{b})$. The contrast in (8) shows that hmá requires that the prejacent be contextually more likely compared to its alternative - that it is more likely for Aung to drink water than for Aung to drink something else in (8a) - and is infelicitous when the prejacent is less likely, as in (8b).

(7) Shared context for examples in this section, (8-15), with two drinks:

There were only two drinks available at the party last night: water and beer. Aung is a child, so he is more likely to drink water than beer.

(8) Scalar hmá:

a. Aun=gá ye=go=hmá mă-thauq-k'éh-da.

Aung $=$ NOM water $=$ ACC $=$ HMÁ NEG-drink-PST-DA $\approx$ 'Aung didn't even drink WATER.'

b. \#Aun=gá $\quad$ biya $=$ go=hmá mă-thauq-k'éh-da.

Aung $=$ NOM beer $=$ ACC $=$ HMÁ NEG-drink-PST-DA

Intended: $\approx$ \# 'Aung didn't even drink BEER.'

This scalar behavior of hmá appears to be similar to that of so-called "scalereversed” even (see e.g., Karttunen \& Peters 1979: pp. 25-27, Rooth 1985: ch. 4, König 1991: pp. 71-73, Rullmann 1997, Giannakidou 2007, Erlewine 2018), which we use in the English translations in (8).

An example of the exhaustive use of hmá is presented in (9), evaluated in the same context (7). (9B) expresses that Aung drank water and that he drank nothing else, disallowing the continuation that Aung also drank beer.

5 See for example Matthewson 2004: p. 391 for relevant discussion, based on the study of a cleft-like construction in St'át'imcets, that advocates against relying on speaker translations. 
In example (9B), the prejacent 'that Aung drank water' is a relatively likely possibility given the context. But unlike in (8), the use of hmá in (9) is not sensitive to the relative likelihood of the prejacent, as indicated by the felicity of ( $\left.9 B^{\prime}\right)$ where the prejacent is less likely. (9B') is also exhaustive, disallowing a continuation that Aung also drank water.

\section{(9) Exhaustive hmá:}

A: I wonder what Aung drank.

B: $A u n=$ gá $\quad$ ye=go=hmá thauq-k'éh-deh.

Aung $=$ NOM water $=$ ACC $=$ HMÁ drink-PST-NFUT

(\# Thu=gá biya=go (=lèh) thauq-k'éh-deh. )

$3=$ NOM beer $=$ ACC $(=$ also $)$ drink-PST-NFUT

₹ 'It's WATER that Aung drank. (\# He also drank beer.)'

B': Aun=gá biya=go=hmá thauq-k'éh-deh.

Aung $=$ NOM beer $=$ ACC $=$ HMÁ drink-PST-NFUT

(\# Thu=gá ye=go (=lèh) thauq-k'éh-deh.)

$3=$ NOM water $=$ ACC $(=$ also $)$ drink-PST-NFUT

$\approx$ 'It's BEER that Aung drank. (\# He also drank water.)'

What determines whether a particular use of hmá will be interpreted as scalar or exhaustive? The examples which yield these different meanings in (8) and (9) above differ in two ways: the scalar (8) is negated and ends with the $t a / d a$ mood marker, whereas the exhaustive (9) is affirmative with default (here, non-future) mood markers.

We might hypothesize that any use of hmá in a negative clause is necessarily scalar. This is incorrect. Consider the examples in (10), again in context (7). The construction here is felicitous with the focus 'water' in (1OB) and 'beer' in (10B') and therefore not scale-sensitive, in contrast to (8) above. These forms in (10B,B') are instead instances of exhaustive hmá taking scope over negation; their exhaustivity is verified by the infelicity of the continuations given below. 
A variably exhaustive and scalar focus particle in Burmese

(10) Exhaustive hmá with local negation: exhaustive $>$ NEG

A: I wonder what Aung didn't drink.

B: Aun=gá ye=go=hmá mă-thauq-k'éh-bù.

Aung $=$ NOM water $=$ ACC $=$ HMÁ NEG-drink-PST-NEG

(\# Thu=gá biya=go (=lèh) mă-thauq-k'éh-bù. )

$3=$ NOM beer $=$ ACC $(=$ also $)$ NEG-drink-PST-NEG

$\approx$ 'It's WATER that Aung didn't drink. (\# He also didn't drink beer.)'

B': Aun=gá biya=go=hmá mă-thauq-k'éh-bù.

Aung $=$ NOM beer $=$ ACC $=$ HMÁ NEG-drink-PST-NEG

(\# Thu=gá ye=go (=lèh) mă-thauq-k'éh-bù. )

$3=$ NOM water $=$ ACC $(=$ also $)$ NEG-drink-PST-NEG

₹ 'It's BEER that Aung didn't drink. (\# He also didn't drink water.)'

Recall that sentential negation mă triggers the use of the negative mood marker $p^{\prime}$ 'ù/bù which is used here in (10). The first sentences of (10B,B') contrast minimally with the scalar hmá examples in (8a,b), respectively, in just this choice of mood marker. With negation and the default negative mood marker $p$ 'ù/bù, we yield exhaustive hmá scoping over negation in (10). With negation and the $t a / d a$ mood marker, we yield the scale-sensitive interpretation observed in (8). As noted above, this correlation between the scalar reading and the use of the mood marker $t a / d a$ for all examples in this section, and more generally in many contexts. We will explain this effect, but also show that these factors are dissociable, in Section 6.

The difference between the two uses of hmá with negation becomes apparent in a context where Aung in fact did not drink anything. Example (11a) below shows that the scalar hmá example in (8) is natural in such a situation, as evidenced by the acceptability of the continuation 'He didn't drink anything. ${ }^{6}$ In contrast, exhaustive hmá scoping over negation in (10) requires that Aung drank everything else, making the same 'He didn't drink anything' continuation unnatural in (11b).

6 However, scalar hmá (the first sentence of (11a)) does not itself require that nothing else was drunk by Aung. See the discussion of example (31) below. 


\section{(11) Scalar and exhaustive hmá with negation, with continuations: ${ }^{7}$}

a. Aun=gá ye=go=hmá mă-thauq-k'éh-da.

Aung $=$ NOM water $=$ ACC $=$ HMÁ NEG-drink-PST-DA

Thu=gá ba=hmá mă-thauq-k'éh-bù.

$3=$ NOM what=HMÁ NEG-drink-PST-NEG

$\approx$ 'Aung didn't even drink WATER (=8a). He didn't drink anything.'

b. Aun=gá ye=go=hmá mă-thauq-k'éh-bù.

Aung $=$ NOM water $=$ ACC $=$ HMÁ NEG-drink-PST-NEG

\# Thu=gá ba=hmá mă-thauq-k'éh-bù.

$3=$ NOM what $=$ HMÁ NEG-drink-PST-NEG

$\approx$ 'It's WATER that Aung didn't drink $(=10 B)$. \# He didn't drink anything.'

The continuation 'He didn't drink anything' involves an NPI 'anything' formed by a wh-word and the particle hmá, which we note in Section 7.

Next we turn to the behavior of hmá embedded under a higher, nonclause-mate negation, as in (12). We observe that this use of hmá is felicitous in context (7) referring to the likely proposition with 'water' or the unlikely 'beer' in its prejacent, and is therefore scale-insensitive.

\section{(12) hmá under higher negation is not scale-sensitive:}

a. [ср Aun=gá ye=go=hmá thauq-k'éh-deh/da]

Aung $=$ NOM water $=$ ACC $=$ HMÁ drink-PST-NFUT $/$ DA

mă-houq-p'ù.

NEG-right-NEG

₹ 'It's false that it's WATER that Aung drank.'

b. [cP Aun=gá biya=go=hmá thauq-k'éh-deh/da]

Aung $=$ NOM beer $=$ ACC $=$ HMÁ drink-PST-NFUT $/$ DA

mă-houq-p'ù.

NEG-right-NEG

$\approx$ 'It's false that it's BEER that Aung drank.'

These examples (12) embed the exhaustive hmá clauses from (9a,b), which are themselves scale-insensitive, under a higher negation. ${ }^{8}$ The fact that (12)

7 One of our speakers allowed for the continuation in (b), but not with the exhaustive interpretation, instead offering a translation akin to what we report in (a). This is understood by our analysis, as the relationship between mood marker choice (the presence or absence of $t a / d a)$ and the interpretation of hmá is not one to one, as we discuss in Section 6. 
A variably exhaustive and scalar focus particle in Burmese

is not scale-sensitive shows that local negation is necessary for the scalar use of hmá in (8) above.

We further investigate the behavior of exhaustive hmá by studying the felicity of the negated exhaustive hmá example in (12a) in more complex utterances. First, we observe in (13a) that (12a) following an assertion that 'Aung drank water' is judged as infelicitous. We note that the behavior of hmá here contrasts sharply from that of the 'only' particle $p$ 'èh/bèh under negation in (13b), which may be used felicitously as a continuation to 'Aung drank water.'

(13) Exhaustive hmá versus p'èh/bèh 'only' under higher negation:

Aung=gá ye=go thauq-k'éh-deh, (da-beméh)

Aung $=$ NOM water $=$ ACC drink-PST-NFUT that-although

'Aung drank water, (but)...'
a. \# ... (thu=gá) ye=go=hmá thauq-k'éh-deh/da
$3=\mathrm{NOM}$ water $=\mathrm{ACC}=$ HMÁ drink-PST-NFUT $/ \mathrm{DA}$
mă-houq-p'ù.
NEG-right-NEG
$\approx$ \# '. . it's false that it's water that he drank $(=12 \mathrm{a})$.'
b. $\ldots$ (thu=gá) ye =go=bèh thauq-k'éh-deh/da
$3=$ NOM water $=$ ACC $=$ ONLY drink-PST-NFUT $/$ DA
mă-houq-p'ù.
NEG-right-NEG
$\approx$ '...it's false that he drank only water.'

This contrast between negated hmá and negated 'only' p'èh/bèh in (13) parallels the contrast between negated it-clefts versus negated only in English:

8 We note that the embedded clauses can end in the regular teh/deh mood marker or $t a / d a$. An anonymous reviewer reports that they would use $t a / d a$ instead of teh/deh, but all five of our consulted speakers accept both here, evaluated in the context. In our discussion and analysis of the ta/da mood marker in Section 6 below, we only discuss its effects in matrix clauses. We leave the description of the semantics of mood marker choice in embedded clauses for future work. 
(14) Negated it-cleft vs negated only in English: (Büring \& Križ 2013: p. 2)

a. \#She invited Fred, but it wasn't Fred she invited.

b. She invited Fred, but she didn't invite only Fred.

We explain the contrast in (13) much in the same way that the English contrast in (14) has been explained. Like English only (Horn 1969), the 'only' particle $p$ 'èh/bèh presupposes its prejacent and makes its exhaustive claim at-issue, allowing higher negation to target the latter alone as in (13b). In contrast, with the embedded exhaustive hmá in (13a), it is the prejacent claim that is at-issue and targeted by negation, explaining its incompatibility with the earlier assertion that Aung drank water.

An important difference between English it-clefts and Burmese exhaustive hmá, however, is that the former but not the latter introduces a presupposition that one of the alternatives must be true. ${ }^{9}$ We see in (15) that the negated exhaustive hmá example (12a) can be followed by 'He didn’t drink anything' without contradiction.

\section{(15) Exhaustive hmá has no existential presupposition:}

$$
\begin{aligned}
& \text { Aun=gá ye=go=hmá thauq-k'éh-deh/da mă-houq-p'ù. } \\
& \text { Aung=NOM water=ACC=HMÁ drink-PST-NFUT/DA NEG-right-NEG } \\
& \text { Thu=gá ba=hmá mă-thauq-k'éh-bù. } \\
& \text { 3=NOM what=HMÁ NEG-drink-PST-NEG } \\
& \approx \text { 'It's false that it's water that Aung drank. (=12a) He didn't drink } \\
& \text { anything.' }
\end{aligned}
$$

We conclude that exhaustive hmá patterns with English it-clefts in making its prejacent rather than exhaustive claim at-issue - supporting our choice to offer it-clefts as approximate translations for exhaustive hmáwith the important caveat that hmá does not introduce an existential requirement.

\section{Proposal}

We propose a uniform semantics for hmá as a not-at-issue scalar exhaustive, similar to the semantics proposed for English it-clefts in Velleman et al.

9 On the strength of the existential inference of English it-clefts, see Križ 2017 sec. 5.2 and references there. We thank an anonymous reviewer for highlighting the importance of this issue. 
A variably exhaustive and scalar focus particle in Burmese

2012. We analyze the descriptively scalar and exhaustive uses of hmá observed above as the result of a scope ambiguity: When hmá takes widest scope (inside the clause), its interpretation is exhaustive. When hmá scopes under negation, the resulting meaning will be scalar, sensitive to the relative likelihood of the prejacent with respect to its alternatives. The apparent correlation with the presence or absence of the sentence-final mood marker $t a / d a$, observed above, will be discussed in Section 6 .

hmá encliticizes to a focus-containing constituent but at LF is adjoined to a propositional node $\alpha$ within the same clause. ${ }^{10}$ In the Roothian Alternative Semantics framework for the evaluation of focus, the prejacent $p=\llbracket \alpha \rrbracket^{0}$, the ordinary semantic value of $\alpha$, and $C \subseteq \llbracket \alpha \rrbracket^{\mathrm{f}}$, the focus semantic value of $\alpha$ (see e.g., Rooth 1992). $C$ must be closed under conjunction and partially ordered by < likely. hmá introduces the not-at-issue requirement in (16), which for concreteness we describe as a presupposition.

(16) Presupposition of hmá:

$$
h a_{C}(p)=\lambda w . \forall q \in C\left[\left(q<_{\text {likely }} p\right) \rightarrow \neg q(w)\right]
$$

where $C$ is closed under conjunction

"No less likely alternative is true."

This meaning in (16) is a version of the MAX operator proposed in Beaver \& Clark 2008: p. 261 and adopted for the not-at-issue part of English it-clefts by Velleman et al. (2012). ${ }^{11}$ See also Coppock \& Beaver 2011, 2014 for its application to other exclusive particles, as we briefly discuss in Section 4.3 below.

Our definition in (16) diverges from their formulations in two ways. First, we propose that the presupposition of hmá (16) is necessarily calculated using a strict partial order of alternatives by likelihood and does not permit other contextually-determined orderings. We will explicitly motivate this choice in Section 4.3, where we show that taun/daun 'even' and p'èh/bèh 'only' may make reference to contextually-determined, non-likelihood-based scales, whereas hmá strictly utilizes likelihood.

Second, our formulation quantifies over a set of Roothian focus alternatives $C$, calculated based on hmá's sister at LF. This contrasts from the formulations in the works above, beginning with Beaver \& Clark 2008 (in turn

10 This can be thought of as hmá moving from its pronounced position, in a clause-bound fashion, or as the pronounced particle hmá agreeing with a covert HMÁ on the clausal spine (see Branan \& Erlewine 2022 and citations there), with this dependency being clause-bound.

11 See also Renans \& De Veaugh-Geiss 2019 for recent discussion and (positive) evaluation of this formulation for cleft semantics in relation to other, homogeneity-based approaches. 
building on Roberts 1996), which refer to the "Current Question" (CQ) as the relevant set of alternatives. We believe that our proposal is in fact compatible with Beaver \& Clark's approach, but here we will nonetheless simply refer to the alternative set $C$, for two reasons. First, we wish to ensure that the set of alternatives strictly reflects hmá's sister at LF, as we specify above. This may be ensured only indirectly if hmá simply refers to the CQ. ${ }^{12}$ Second, this choice allows us to simplify some of our presentation in Section 6, where we discuss at some length the different Questions Under Discussion (QUDs) that different hmá utterances directly and indirectly address. Careful readers will notice there that the alternative set $C$ - which by Beaver \& Clark's formulation should reflect the "Current Question" - will often be different from the immediate QUD. This too would not necessarily be a problem if we were to adopt Beaver \& Clark's theory, as they allow for the accommodation of CQ (see their pp. 39-40) and for the CQ to be congruent to proper subparts of the utterance, rather than to the whole utterance itself (see for instance their pp. 45-46). Nonetheless, these mismatches between the CQ and the QUDs under discussion have the potential to make the discussion there more confusing, so we opt instead to simply refer to the alternative set $C$ throughout.

The requirement that the alternative set $C$ be closed under conjunction is shared with these prior works. In particular, it accomplishes the same function as the assumption, discussed explicitly by Coppock \& Beaver (2011: 199, 2014: 381), that the set of alternatives in Current Question is organized into a boolean lattice. The idea that focus particles can lexically specify the shape of the alternatives that it quantifies over, including the relevant ordering relation, has been previously mooted by Coppock \& Beaver (2014), as we discuss in Section 4.3 below.

\subsection{Exhaustive hmá}

We first consider the exhaustive use of hmá, demonstrating with simple affirmative sentences. We will first model the behavior of example (1/9B) above, repeated here as (17).

12 Beaver \& Clark do observe that this is generally the case: "In typical examples we have considered involving focus sensitivity of propositional operators, it is the argument of the operator which is congruent to the CQ" (p. 129). To be fair, this restriction is also not enforced by the widely adopted theory of Rooth 1992, which allows for adjunction of $\sim C$ at different points in the structure, not only to the operator's sister. 
A variably exhaustive and scalar focus particle in Burmese

(17) Exhaustive hmá with prejacent 'Aung drank water': $=(1 / 9 \mathrm{~B})$

Aun=gá $\quad$ ye=go=hmá thauq-k'éh-deh.

Aung $=$ NOM water $=$ ACC $=$ HMÁ drink-PST-NFUT

$\approx$ 'It's WATER that Aung drank.'

Based on the context considered in Section 3, repeated below, we let the set of alternatives $C$ contain two atomic alternatives, $A=$ 'that Aung drank water' and $B=$ 'that Aung drank beer', as well as their conjunction $A \wedge B$. The conjunctive alternative is necessarily less likely than each atomic alternative. In addition, given the contextual information that Aung is a child, $A>{ }_{\text {likely }} B$.

\section{(18) Alternatives $C$ in context (7):}

Context (7): There were only two drinks available at the party last night: water and beer. Aung is a child, so he is more likely to drink water than beer.

$$
\begin{aligned}
& C=\{A, B, A \wedge B\} \\
& A=\text { 'that Aung drank water' }>_{\text {likely }} \quad B=\text { 'that Aung drank beer' } \\
& \checkmark \text { likely } \quad \checkmark_{\text {likely }} \\
& A \wedge B=\text { 'that Aung drank water and beer' }
\end{aligned}
$$

At LF, hmá takes the clause 'Aung drank [water] $]_{\mathrm{F}}$ ' as its sister, so the prejacent $p=A$. Given the alternatives $C$ from (18), hmá will assert the prejacent $A$ and presuppose that no less likely alternative is true. There are two less likely alternatives, $B$ and $A \wedge B$, resulting in the presupposition in (19b):

\section{(19) Computing hmá in (17):}

LF: [ hmá [Aung WATERF drank]]
a. asserts: $A$
b. presupposes: $h m a_{C}(A)=\neg(A \wedge B) \wedge \neg B=\neg B$
$\Rightarrow$ exhaustive

We predict that (17) will assert the prejacent $A$ and presuppose the negations of $B$ and $A \wedge B$. The combined result is an cleft-like exhaustive claim: Aung drank water (at-issue) and did not drink anything else (not at-issue).

Now consider instead if the prejacent were $B$, 'that Aung drank beer', in the same context with alternatives $C$ in (18). This corresponds to the use of 
hmá in (20) below, repeated from (9B') above. In this case, when computing the presupposition of $h m a$, there is only one alternative that is less likely than the prejacent: the conjunctive alternative $A \wedge B$.

(20) Exhaustive hmá with prejacent 'Aung drank beer’:

Aun=gá $\quad$ biya $=$ go $=$ hmá thauq-k'éh-deh.

Aung $=$ NOM beer $=$ ACC $=$ HMÁ drink-PST-NFUT

₹ 'It's BEER that Aung drank.'

(21) Computing hmá in (20):

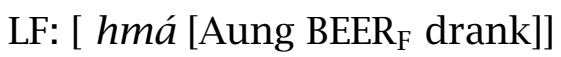

a. asserts: $B$

b. presupposes: $h_{m a ́}(B)=\neg(A \wedge B)$

$\Rightarrow$ exhaustive

This results in the assertion of $B$ and the presupposition of $\neg(A \wedge B)$. However, taken together, these requirements entail that $A$ must be false.

We thus see that, when taking widest scope, the scalar meaning in hmá in (16) results in an exhaustive interpretation for both a more likely prejacent ( $A$ with 'water') and a less likely prejacent ( $B$ with 'beer'). Even if the context supports a partial order with $A$ and $B$ left unordered, or if the relative likelihood of $A$ and $B$ is unknown, hmá will still presuppose the negation of the conjunctive alternative, $\neg(A \wedge B)$, resulting in exhaustive semantics.

\section{2 hmá in negative clauses}

Next we consider the behavior of hmá in the presence of local negation. We propose that both scope possibilities hmá $>$ NEG and NEG $>$ hmá are possible at LF. hmá > NEG will yield a cleft with negation in its scope. In contrast, NEG $>$ hmá will yield the scalar use of hmá described above.

\subsubsection{Exhaustive hmá over negation (hmá > NEG)}

We begin first with the consideration of hmá > NEG scope, which will derive a cleft with negation in its scope. This is the case of example (22), repeated from (10B) above. 
A variably exhaustive and scalar focus particle in Burmese

(22) Exhaustive hmá with scope over negation:

Aun=gá $\quad$ ye=go=hmá mă-thauq-k'éh-bù.

Aung $=$ NOM water $=$ ACC $=$ HMÁ NEG-drink-PST-NEG

$\approx$ 'It's WATER that Aung didn't drink.' exhaustive $>$ NEG

Following the notation from above $(A=$ 'that Aung drank water', $B=$ 'that Aung drank beer'), $C$ will now include the negated atomic alternatives $\neg A$ and $\neg B$, as well as the conjunctive alternative $\neg A \wedge \neg B$. Again following the context in (7), the atomic alternatives are ordered $\neg A<$ likely $\neg B$ and the conjunctive alternative is again less likely than each atomic alternative.

(23) Alternatives $C$ in context (7), with negation in scope:

$C=\{\neg A, \neg B, \neg A \wedge \neg B\}$

$\neg A=$ 'Aung didn't drink water' <likely $\neg B=$ 'Aung didn't drink beer'

$\checkmark$ likely $\quad L_{\text {likely }}$

$\neg A \wedge \neg B=$ 'Aung didn't drank water and didn't drink beer'

The use of hmá with prejacent $\neg A$ or $\neg B$ will both yield an exhaustive interpretation, just as hmá did without negation in (19) and (21) above. Here we illustrate the case of $p=\neg A$, corresponding to example (22) above. The presupposition of hmá will require that the conjunctive alternative $\neg A \wedge \neg B$ be false. Together with the assertion that Aung didn't drink water $(\neg A)$, we yield the exhaustive claim that water is the only thing that Aung didn't drink.

(24) Computing hmá in (22), hmá > NEG:

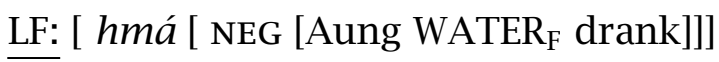

a. asserts: $\neg A$

b. presupposes: $h m a_{C}(\neg A)=\neg(\neg A \wedge \neg B)=A \vee B$

$\Rightarrow$ exhaustive $>$ NEG

We similarly yield an exhaustive claim if $h m a ́$ applies to $\neg B$ : 
(25) Computing hmá, hmá > NEG, with prejacent $\neg B$ :

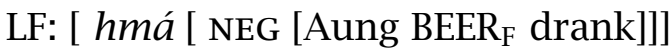

a. asserts: $\neg B$

b. $\quad$ presupposes: $h_{m a ́}(\neg B)=\neg(\neg A) \wedge \neg(\neg A \wedge \neg B)=A \wedge(A \vee B)$

$\Rightarrow$ exhaustive $>$ NEG

Following the logic of (19) and (21) above, hmá in both (24) and (25) result in an exhaustive claim of their prejacent. hmá with scope over negation is compatible with both more likely alternatives and less likely alternatives as its prejacent; that is, it is not scale-sensitive.

\subsubsection{Scalar hmá (NEG > hmá)}

We now consider the contribution of hmá with scope under negation. In contrast to the uses of hmá modeled above, which uniformly contribute exhaustivity, we argue that the NEG > hmá configuration results in the descriptively scale-sensitive use of hmá akin to so-called scale-reversed 'even'. Concretely, we will model the behavior of hmá in the examples in (8) above, repeated here in (26):

(26) Scalar hmá:

a. Aun=gá ye=go=hmá mă-thauq-k'éh-da.

Aung $=$ NOM water $=$ ACC $=$ HMÁ NEG-drink-PST-DA

$\approx$ 'Aung didn't even drink WATER.'

b. \#Aun=gá biya =go=hmá mă-thauq-k'éh-da.

Aung $=$ NOM beer $=$ ACC $=$ HMÁ NEG-drink-PST-DA

Intended: $\approx$ \# 'Aung didn't even drink BEER.'

Because negation is outside of the scope of hmá, the relevant set of alternatives $C$ will be without negation as in (18) above, repeated here in (27). The two atomic alternatives are again ordered with $A>{ }_{\text {likely }} B$, since the context (7) assumes Aung to be a child and therefore more likely to drink water than beer. 
A variably exhaustive and scalar focus particle in Burmese

(27) Alternatives $C$ in context (7), below negation:

$C=\{A, B, A \wedge B\}$

$$
\begin{gathered}
A=\text { 'that Aung drank water' }>_{\text {likely }} \quad B=\text { 'that Aung drank beer' } \\
\checkmark_{\text {likely }} \\
A \wedge B=\text { 'that Aung drank water and beer' }
\end{gathered}
$$

We now compute the LFs for (26a,b), with $A$ and $B$ in turn as the prejacent. In (26a), the prejacent is the more likely alternative, $A$, and the example is judged as felicitous in this context. We predict that hmá presupposes the negation of $B$ as well as the negation of the conjunction $A \wedge B$ (28b). The higher negation will negate the at-issue content $A$ (28a), but will not affect the presupposition introduced by hmá.

(28) Computing hmá in (26a), NEG > hmá (felicitous):

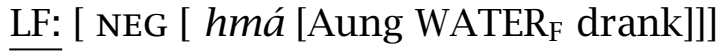

a. asserts: $\neg A$

b. presupposes: $h \operatorname{má}_{C}(A)=\neg(A \wedge B) \wedge \neg B=\neg B$

The overall meaning computed for (26a) in (28) is one which we would not describe as "exhaustive", following our descriptive heuristic for this term introduced in Section 3, and will be compatible with a context where Aung did not drink anything. We saw that example (26a) indeed is felicitous in such a context, in (11a) above. Importantly - for reasons that we make clear in a moment - we note that the presuppositional $\neg B$ requirement of (26a) in (28b) is logically independent of its at-issue requirement (28a), and would be absent if not for the presence of hmá.

Next we turn to the interpretation of example (26b), which is judged as infelicitous in our context. With the less likely alternative $B$ as the prejacent, hmá simply presupposes the negation of the conjunctive alternative $A \wedge B$, as this is the only alternative that is less likely than the prejacent in $C(29 \mathrm{~b})$. This presupposition will project through negation. The at-issue content $B$ is negated, resulting in the assertion of $\neg B$ in (29a).

(29) Computing hmá in (26b), NEG > hmá (infelicitous):

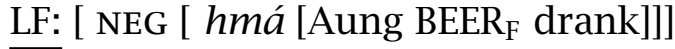

a. asserts: $\neg B$

b. presupposes: $h_{m a ́}(B)=\neg(A \wedge B)$ 
Notice that, in (29), the predicted assertion $\neg B$ entails the predicted presupposition of $h m a ́$ $\neg(A \wedge B)$. We therefore predict that in any context where (26b) can be uttered felicitously and truthfully, the use of the particle hmá will not contribute to the overall meaning of the utterance. The truth of the assertion $\neg B-$ which can also be expressed without hmá - will itself guarantee that the condition introduced by hmá is met, making the addition of hmá vacuous. We suggest that this vacuity is the source of the infelicity of (26b) in its context.

More formally, we adopt the view that the adjunction of focus particles such as hmá are governed by a Non-Vacuity condition such as (30) from Crnič 2011a,b. ${ }^{13}$

(30) The Principle of Non-Vacuity (Crnič 2011a: p. 110, 2011b: p. 7):

The meaning of a lexical item used in the discourse must affect the meaning of its host sentence (either its truth-conditions or its presuppositions).

To evaluate a use of hmá for Non-Vacuity, we compare its overall meaning contribution to that of the utterance without hmá. The addition of hmá in (28) is contentful, as it expresses presuppositional content beyond the commitments made by the speaker in their assertion. The same goes for the use of hmá in the descriptively exhaustive uses in (19) and (21) above. However, the addition of hmá is not contentful in (29): The presupposition introduced by $h m a ́, ~ \neg(A \wedge B)$, is logically weaker than the assertion and therefore its addition in (29) is uninformative. A Non-Vacuity principle such as in (30) successfully rules out the use of hmá in (26b).

The end result is that the felicity of hmá scoping under negation will depend on the relative position of the prejacent with respect to its contextuallydetermined alternatives on the scale of likelihood. hmá is infelicitous when the prejacent is the least likely alternative, as in (29). The direction of this asymmetry also explains why, in the basic case, scalar hmá is naturally translated into English with scale-reversed even.

A prediction of the present analysis is that hmá does not require its prejacent to be at an extreme end of the scale. hmá only requires that there exists at least one less likely alternative in the set of alternatives $C$ which will be meaningfully excluded by the addition of hmá. In the following example, the context is set up so that there are three alternatives on a scale. Scalar hmá

13 See also Alxatib 2020: pp. 44-51 and Erlewine \& Lim 2020 for independent motivation for Non-Vacuity constraints on focus particles and other adjoined material. 
A variably exhaustive and scalar focus particle in Burmese

can be grammatically used to target the middle alternative, with 'tea', presupposing the negation of 'Aung drank beer', the least likely alternative. The felicity of the continuation 'He drank water' serves to show that hmá in (31) does not exclude the most likely alternative, with 'water'. ${ }^{14}$

\section{Scalar hmá does not require the end of the scale:}

Context: There is a party with water, tea, and beer. Aung is a child, so he is most likely to drink water, also likely (but less likely) to drink tea, and least likely to drink beer.

$$
\begin{aligned}
& \text { Aun=gá lăp'eq-ye=hmá mă-thauq-k'éh-da. } \\
& \text { Aung=NOM tea-water=HMÁ NEG-drink-PST-DA } \\
& \text { literally 'Aung didn't drink HMÁ tea.' }
\end{aligned}
$$$$
\text { Thu=gá ye=go thauq-k'éh-deh. }
$$$$
3=\text { NOM water }=\text { ACC drink-PST-NFUT }
$$

'He drank water.'

It's worth noting that it's not always the case that hmá within the scope of negation leads to such a scale-sensitive asymmetry on its felicitous use. See (32) below, where hmá is in an embedded clause, under matrix negation. Both variants of (32), repeated from (12), with 'water' or 'beer' as the focus, are felicitous in the same context. We propose that Non-Vacuity is evaluated cyclically, at the completion of each clause or phase. ${ }^{15}$ In example (32), the addition of hmá is meaningful at the embedded CP level, regardless of the choice of focus, licensing the use of hmá. This whole meaning is then negated by the higher negation.

14 This data point is important for ruling out the possibility that scalar hmá is a particle that simultaneously introduces a scalar inference (that the prejacent is the most likely alternative, akin to that of scale-reversed even) and an independent, non-scalar exhaustive inference (that all other alternatives are false). We discuss the Samish particle ?al' in Section 5 below.

This behavior also seems to importantly contrast from the behavior of English even, which does require its prejacent to be at the end of the scale, at least amongst alternatives explicitly mentioned in the preceding context. See especially examples (7) and (8) in Greenberg 2016: p. 4.

15 Although here we only discuss cyclic evaluation by clause, Erlewine \& Lim 2020 argues that Non-Vacuity of this form also applies cyclically at the DP level, based on facts regarding nominal interpretation in Burmese. 
(32) hmá under non-local negation is not scale-sensitive:

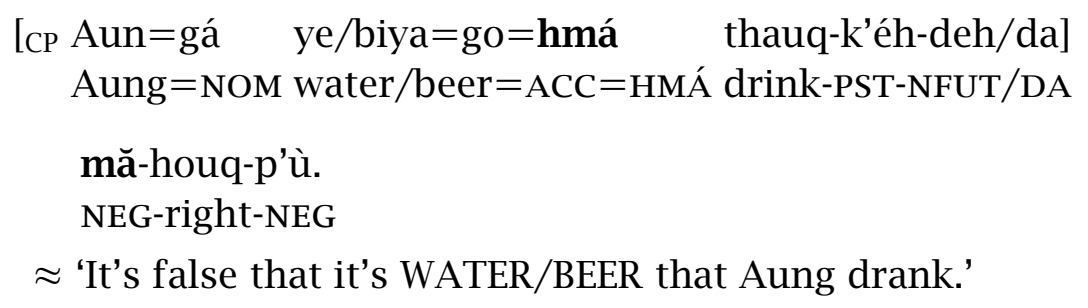

Together with the independently motivated Non-Vacuity condition (30), our uniform analysis for the semantics of hmá as a not-at-issue scalar exhaustive successfully derives the observed behavior of hmá, in both its exhaustive and scalar uses. These patterns are summarized in the table below.

(33) Summary:

$$
\begin{aligned}
& C=\{A, B, A \wedge B\}, A>_{\text {likely }} B
\end{aligned}
$$

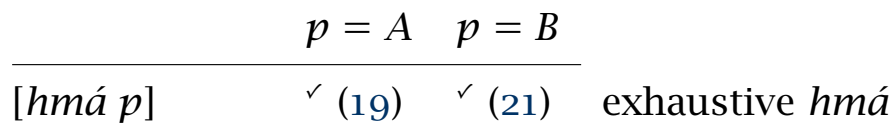

$$
\begin{aligned}
& \text { [hmá [NEG } p \text { ]] } \quad \checkmark(24) \quad \checkmark(25) \quad \text { exhaustive hmá > NEG } \\
& \text { [NEG [hmá p]] } \quad{ }^{\checkmark}(28) \quad *(29) \quad \text { scalar hmá }
\end{aligned}
$$

\section{3 (In)sensitivity to contextual scales}

We have proposed and demonstrated how a uniform semantics for hmá underlies both the descriptively scalar and exhaustive uses of hmá. The key to this proposal is the scalar exhaustive presupposition of hmá, repeated here as (34). Within the local scope of negation, Non-Vacuity ensures that hmá is only felicitous if its prejacent is more likely than some other alternative which is false. In other cases, it introduces a non-scale-sensitive, cleft-like exhaustivity requirement.

\section{(34) Presupposition of hmá:}

$$
h_{m} a_{C}(p)=\lambda w . \forall q \in C\left[\left(q<_{\text {likely }} p\right) \rightarrow \neg q(w)\right]
$$

where $C$ is closed under conjunction

"No less likely alternative is true."

As noted above, this semantics in (34) is modeled in part on the scalar exhaustive operator MAX proposed for only (Beaver \& Clark 2008), it-clefts 
A variably exhaustive and scalar focus particle in Burmese

(Velleman, Beaver, Destruel, Bumford, Onea \& Coppock 2012), and other exclusive particles (Coppock \& Beaver 2011, 2014) in English, reproduced in $(35):^{16}$

(35) Scalar exhaustive MAx:

(Velleman et al. 2012: p. 451)

$\operatorname{MAX}_{S}(p)=\lambda w . \forall q \in \mathrm{CQ}_{S}\left[\left(q>_{S} p\right) \rightarrow \neg q(w)\right]$

In contrast to earlier, non-scalar analyses of only (e.g., Horn 1969) which simply claim that all alternatives not entailed by the prejacent are false, MAX makes reference to a contextually-determined ordering relation $>_{S}$ and claims that all alternatives that are "stronger" than the prejacent $p\left(>_{s} p\right)$ are false. In the basic case, the ordering may be asymmetric entailment or likelihood: for example, $p>_{s} q$ iff $p<$ likely $q$. However, the ordering could also be another, non-logical ordering made salient by the context $S$, which allows for a natural extension to so-called scalar uses of exhaustive particles.

We present two examples in (36) which illustrate such scalar uses of exhaustive particles in English, both involving reference to a conventionalized rank order (Horn 1989: p. 546): in (36a), military ranks in the US Navy, and in (36b), implied "ranks" in academic status.

\section{(36) Rank-order uses of English only:}

a. She only became a chief petty officer. (Beaver \& Clark 2008: p. 260)

b. John is only/just a graduate student.

(Coppock \& Beaver 2014: p. 378)

The meaning computed by the use of only and just here makes use of this rank order. For instance, regarding the meaning of (36a), Beaver \& Clark (2008) note, “we don't mean she never became a petty officer third class (a lower US naval rank), but rather that she never proceeded any further, e.g., never becoming the Master Chief Petty Officer of the Navy" (p. 26o). Similarly, Coppock \& Beaver (2014) note that (36b) does not necessarily imply that John does not have any other relevant property or rank, but rather than he is "at most" a graduate student.

Based on such data, Coppock \& Beaver $(2011,2014)$ argue that the scalar exhaustive MAX (35) constitutes the common core of exhaustive particle

16 As noted above, Beaver and colleagues' MAX quantifies over the current question $\mathrm{CQ}_{s}$, whereas we refer to the focus alternative set $C$. This difference is orthogonal to our discussion here. 
meanings, where the ordering $>_{S}$ will be determined by the context. They furthermore propose that individual particles may lexically specify or restrict the type of orderings that they may make reference to, noting for example that English merely must use a rank-order scale and also that, for at least some speakers, the rank-order use in (36b) is more natural with just than with only. The question of what ordering(s) the meaning of English even makes reference to - for instance, whether it marks the prejacent as less likely than other other alternatives (Karttunen \& Peters 1979) or more 'informative' (Kay 1990) or more 'noteworthy' (Herburger 2000), etc. - has also received significant attention; see for example Greenberg 2016 and references there for discussion.

Against this backdrop, we now explicitly motivate our claim that the scalar exhaustive meaning of Burmese hmá is necessarily calculated using a likelihood ordering, as in (34) above. In particular, we will show that hmá contrasts from the particles taun/daun 'even' and p'èh/bèh 'only' in Burmese in its inability to make use of rank-order scales. In order to clearly distinguish between likelihood and a pragmatic ordering such as a rank order, we consider utterances in the context of a game of dice, where both world knowledge and discourse goals will serve to make salient an ordering from one to six. However, assuming a fairly weighted die, the likelihood that each number between one and six will come up is equal.

We first consider the context and utterances in (37). Here the speaker has rolled a two, where higher numbers are better. Utterances that correspond to 'I didn't even get a three' or 'I only got a two' are judged as felicitous (37a,b), but the corresponding utterance with hmá and negation in $(37 \mathrm{c})$ is judged as unnatural, regardless of the choice of final mood marker.

(37) Dice game: Phyo rolls 2

Context: Phyo and Hla Hla are playing a game of dice, where the person who rolls the higher number wins. Phyo rolls 2, sighs, turns to his friend Maung Maung, and says:

a. Nga=gá nanbaq-thoùn=go=daun mă-yá-géh-bù.

$1=$ NOM number-three $=$ ACC $=$ EVEN NEG-get-PST-NEG

'I didn't even get a three.'

b. Nga=gá nanbaq-hniq=ko=bèh yá-géh-deh $1=$ NOM number-two $=$ ACC $=$ ONLY get-PST-NFUT

'I only got a two.' 
A variably exhaustive and scalar focus particle in Burmese

c. \#Nga=gá nanbaq-thoùn=go=hmá mă-yá-géh-bù/da.

$1=$ NOM number-three $=$ ACC $=$ HMÁ NEG-get-PST-NEG/DA

literally 'I didn’t get HMÁ three.'

We contrast the pattern of judgments in (37) above with that in (38), where the speaker rolls a relatively high number, five. Notably, the equivalent of 'I didn't even get a four' in (38a) - parallel to (37a) above - is judged as infelicitous in the context in (38). Speakers also judge (38b) 'I only got a five' to be degraded in comparison to (37b) above, reflecting the relatively "strong" prejacent in (38b).

\section{(38) Dice game: Phyo rolls 5}

Context: Phyo and Hla Hla are playing a game of dice, where the per-

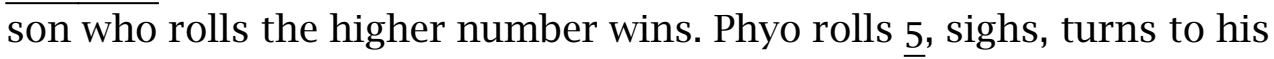
friend Maung Maung, and says:
a. \#Nga-gá nanbaq-lè=go=daun mă-yá-géh-bù. 1 -NOM number-four $=$ ACC $=$ EVEN NEG-get-PST-NEG 'I didn't even get a four.'
b. \#Nga-gá nanbaq-ngà=go=bèh yá-géh-deh. 1 -NOM number-five $=$ ACC $=$ ONLY get-PST-NFUT 'I only got a five.'
c. \#Nga-gá nanbaq-lè=go=hmá mă-yá-géh-bù/da. 1 -NOM number-four $=$ ACC $=$ HMÁ NEG-get-PST-NEG/DA literally 'I didn't get HMÁ four.'

These contrasts in acceptability between the pairs (37a,38a) and (37b,38b) clearly show that taun/daun 'even' and p'èh/bèh 'only' are able to make reference to pragmatic, rank-order scales. In contrast, we see that scalar hmá cannot be used felicitously in either of these contexts, in (37c) and (38c). We argue that this is predicted by our account, where hmá necessarily makes reference to a likelihood ordering and cannot use other contextually salient orderings, in turn supporting this aspect of our analysis.

Let us compute the predicted contribution of hmá in $(37 \mathrm{c} / 38 \mathrm{c})$. Let the relevant set of alternatives be $C=\{1,2,3,4,5,6\}$, where $1,2,3 \ldots$ stand in for the propositions of the form 'that I got (rolled) a one', etc. With hmá taking scope below negation (for scalar hmá), hmá will introduce a presupposition that all alternatives that are less likely than 3 are false (34). However, none of the alternatives in $C$ are ordered by $<_{\text {likely }}$ with respect to any others, as 
these propositions are equally likely. ${ }^{17}$ The predicted presupposition of hmá is thus necessarily vacuous. ${ }^{18}$

\section{(39) Computing scalar hmá in (37c/38c):}

LF: [ NEG [ hmá [ ${ }_{3}$ three $e_{F}$ got]]]
a. asserts: $\neg 3$
b. presupposes: $h m a_{C}(3)=\top$ (no presupposition)

The vacuous meaning contribution of hmá in (39) means that the addition of hmá in this structure will be blocked by Non-Vacuity (30), thus correctly explaining the infelicity of scalar hmá with equally likely alternatives in (37c/38c) above. If hmá were able to make use of a contextually-salient ordering instead, we may expect it to have some productive scalar use in our dice game contexts, just as the Burmese equivalents of 'even' and 'only' do. We leave a full exploration of these particles taun/daun 'even' and p'èh/bèh 'only' for future work.

\section{Cross-linguistic applications}

A number of other languages have focus particles with behavior similar to that of Burmese hmá described in this paper. In each of these cases, a particle has scalar or exhaustive interpretations in the context of local negation, but only an exhaustive interpretation in affirmative clauses. Although we do not develop full analyses for each particle below, their behaviors below strongly support our analysis for Burmese hmá as a more general approach to the behavior of such particles cross-linguistically.

17 A reviewer asks whether our formulation for hmá (34) could instead be formulated to claim that all non-prejacent alternatives that are less than or equally likely as the prejacent ( $\leq$ likely $p$ ) are false. The infelicity of hmá in (37c/38c), where all relevant alternatives are clearly equally likely, serves to support our formulation using the strict partial order $<_{\text {likely. The }}$ alternative formulation described here would falsely predict scalar hmá to be felicitous here.

18 Here we discuss $C$ as not closed under conjunction, as the atomic propositions are known to be mutually exclusive, but including conjunctive alternatives does not improve the situation. Notice that any alternative of the form $m \wedge n$ will have probability zero. Such alternatives are necessarily less likely than the prejacent, so if they are included in $C$, hmá will presuppose their negation, $\neg(m \wedge n)$. However, as $m \wedge n$ is necessarily false, $\neg(m \wedge n)$ is necessarily true, and so these additional claims in the presupposition will be tautologous and not guard against the Non-Vacuity violation. We conclude that - with knowledge of the mutual incompatibility of the atomic alternatives - the use of hmá will be vacuous here, whether $C$ is formally closed under conjunction or not. 
A variably exhaustive and scalar focus particle in Burmese

We first consider the behavior of Blackfoot ikak, which appears as part of the verbal complex. Bliss (2010, 2013) observes that in the absence of negation, ikak is unambiguously interpreted as an exhaustive particle, translated by Bliss using English 'only' (40). ${ }^{19}$

\section{(40) Exhaustivity with Blackfoot ikak:}

$\mathrm{Na} \quad$ Doris káksinsskaka'pssiwa.

anna-wa Doris ikak-inasskaka'pssii-wa

DEM-PROX Doris IKAK-be.tidy.AI-PROX

'Doris is only tidy.' (i.e., not friendly and clever)

In the presence of negation, ikak yields an exhaustive or scalar interpretation, depending on its linear order with respect to negation. Negation can be expressed in Blackfoot using the higher, clausal negator máát or the lower, predicate negator sa. Bliss shows that máát necessarily precedes ikak, with ikak then giving the sentence a scalar meaning, translated by Bliss using 'even' (41a). The predicate negator sa can precede or follow ikak. If sa precedes ikak, the sentence is again interpreted with a scalar flavor (41b). If sa follows ikak, ikak again introduces an exhaustive meaning, which then scopes over negation (42).

\section{(41) NEG > ikak yields a scalar meaning:}

a. Anna Carmelle máátsikakohkottsinooyiiwa

(ibid.: p. 232)

$$
\text { ann-wa Carmelle maat-ikak-ohkott-inoo-yii-wa }
$$

DEM-PROX Carmelle NEG-IKAK-ABL-see.TA-3:4-PROX

$$
\begin{array}{ll}
\text { anniskayi } & \text { pítaay. } \\
\text { ann-yi-hk-ayi } & \text { piitaa-yi } \\
\text { DEM-OBV-INVIS-ayi eagle-OBV }
\end{array}
$$

'Carmelle can't even see that eagle.'

19 Here we reproduce Bliss's examples as presented, with first lines reflecting surface forms and second lines giving underlying phonological forms for each morpheme. Abbreviations in the glosses for these examples, taken from Bliss 2013, include $\mathrm{ABL}=$ ability modal, $\mathrm{AI}=$ animate intransitive, CONJ = conjunct order, IC = initial change, INVIS = invisible, OBV = obviative, TA = transitive animate, as well as others that follow the Leipzig glossing conventions. See Bliss 2013 and references there for more on these elements as well as relevant phonological processes. 
b. Anna Carmelle ínikksiistapoowa

(ibid.: p. 13) anna-wa Carmelle ii-inikk-miistap-oo-wa

DEM-PROX Carmelle IC-angry-away-go.AI-PROX

kámsaikaksaapi'si pí́taa.

kam-sa-ikak-yaapsi-hsi piitaa

if-NEG-IKAK-see.AI-CONJ eagle

'Carmelle will leave angry if she doesn't even see an eagle.'

(42) Ikak > NEG yields exhaustive meaning: ） (ibid.: p. 13)

$\mathrm{Na} \quad$ Doris kaksáínskaka’pssiwa.

an-wa Doris ikak-sa-insskak-a'pssi-wa

DEM-PROX Doris IKAK-NEG-tidy-be.AI-PROX

'Doris is only not tidy.' (i.e., she’s friendly and clever; she’s only not tidy.)

Blackfoot $i k a k$ is a strong candidate for the adoption of our analysis for Burmese hmá. In particular, Bliss (2013, p.c.) observes that the scope of preverbal operators generally tracks their linear order in the Blackfoot verbal complex. The disambiguation of the interpretation of ikak based on its linear order with respect to negation $(41-42)$ thus adds further support to our analysis, which treats such alternations of variably exhaustive and scalar particles as reflecting a scope ambiguity with respect to negation.

A similar pattern is observed in Hindi with the focus particle hi. Bhatt (1994) and Bajaj (2016) ${ }^{20}$ observe that the Hindi particle $h i$ has an exclusive use in basic examples, as in (43). (Although this exhaustive use of hi is translated as 'only' in both of these works, discussion in Bhatt 1994: p. 11 suggests that it might behave more like a cleft.)

(43) Exhaustivity with Hindi hi:

(Bhatt 1994: p. 1)

$$
\begin{aligned}
& \text { Ram }=\text { ne }=\text { hi } \quad \text { Sita=ko dekha. } \\
& \text { Ram }=\text { ERG=HI Sita=ACC see.PST } \\
& \text { 'Only Ram saw Sita.' }
\end{aligned}
$$

However, in the context of negation, $h i$ is ambiguous between exhaustive and scalar readings, translated by Bhatt using English 'only' and 'even' (44). According to Bhatt (1994), the exhaustive > NEG reading is more accessible if

20 Bajaj (2016) also discusses other "intensifier" uses of hi, which we set aside here. 
A variably exhaustive and scalar focus particle in Burmese

the object is scrambled, but experimental work in Bajaj 2016 reveals that this reading is in fact also possible without scrambling. Based on our analysis of Burmese hmá, we suggest that the observed ambiguity in (44) also arises due to a scope ambiguity with respect to negation.

\section{(44) Ambiguity of Hindi hi with negation:}

[Ram ke-paas $]=$ hi bandook nahin hai.

Ram with =HI gun NEG be.PRS

a. 'Only Ram doesn't have a gun.' or

b. 'Even Ram doesn't have a gun.'

Deo $(2014,2020)$ describes the behavior of the Marathi enclitic $c$, which she notes closely parallels that of Hindi $h i$. In some cases, $c$ gives rise to an exhaustive reading, described as introducing a "nothing other than" inference (Deo 2014: p. 7), which is variably translated by Deo using 'only' (45a) or with a cleft (45b). But Marathi $c$ leads to a scalar meaning in other examples, such as (46). Although Deo does not point it out, it appears from the data provided that the scalar interpretation always cooccurs with negation.

(45) Exhaustive Marathi $c$ :

(Deo 2014)

a. Context: What did Anu bring to the potluck?

Anu=ne pulāv $=$ ac āṇ-lā.

$\mathrm{Anu}=$ ERG rice.NOM.SG $=\mathrm{C}$ bring-PRF.M.SG

'Anu only brought rice.'

b. Context: The police have now proved that...

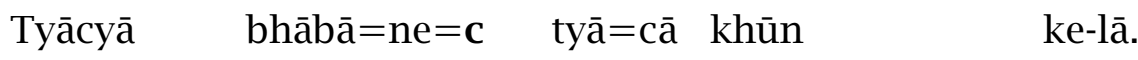

his.OBL.M.SG brother $=\mathrm{ERG}=\mathrm{C}$ he $=$ GEN murder.NOM.M.SG do-PRF

'It was (definitely) his brother who murdered him.'

(46) Scalar Marathi $c$ :

(ibid.)

Context: Did his friends help him out of his financial problems?

Nāhī, tyācyā $\quad$ bhāvā=ne $=\mathbf{c} \quad$ tyā $=$ lā madat

NEG his.OBL.M.SG brother $=\mathrm{ERG}=\mathrm{C}$ he $=\mathrm{DAT}$ help.NOM.F.SG

ke-l-ī nāhì.

do-PRF-F.SG NEG

'No, even his brother didn't help him (let alone his friends).' 
However, unlike Burmese hmá, Deo shows that Marathi $c$ allows for rankorder uses. Example (47) is an instance of exhaustive $c$ making reference to the scale of positions on the bureaucratic ladder:

(47) Marathi $c$ has rank-order uses:

(Deo 2020)

Context: I am wondering if Anu can help me get in contact with the Indian minister for cultural affairs. I ask my friend: 'Is she highly placed in the bureaucracy?'

Nahi, ti $\quad\left[\operatorname{sād}^{h_{i}} \quad\right.$ kārkun] $=\partial c$ āhe

no she simple clerk $=\mathrm{C}$ be.PRS.3SG

'No, she is just a simple clerk.'

Deo 2014 proposes that $c$ associates with the "strongest true alternative" among the set of propositional alternatives, compatible with our description of hmá (16/34) as requiring that no less likely alternative be true, but does not highlight the role of negation in its scalar uses. We suggest that our description of Burmese hmá as a not-at-issue scalar exhaustive - although without the restriction to alternatives ordered by likelihood - may also apply to Marathi $c$ and help explain the distribution of its exhaustive and scalar uses.

Finally, we discuss the particle ?al' in Samish (a dialect of Northern Straits Salish) described in Shank 2003 and also briefly discussed in Guerzoni 2003. ${ }^{21}$ Shank (2003) describes ?al' as being appropriately translated as 'just' in affirmative clauses but as 'even' in negative clauses. Two of his first examples are reproduced in (48) and (49) below. For example (49), we describe the prejacent of ral' as 'that he saw his grandparents' without negation, and its alternatives also without negation.

(48) Samish ?al' as 'just':

(Shank 2003: p. 158)

híẇl' sən ?al' ?ə mətúliyə?.

go.to 1SG.SBJ PAL' OBL Victoria

'I’m just going to Victoria.'

21 Shank (2003) uses the abbreviations LNK = "link" for the initial marker in (49), which is described as having certain quantificational functions, with "an amazingly wide distribution in the language" (p. 172), and PRT = particle. Other glosses here follow the Leipzig glossing rules. 
A variably exhaustive and scalar focus particle in Burmese

(49) Samish ?al' as 'even' with negation:

(ibid.)

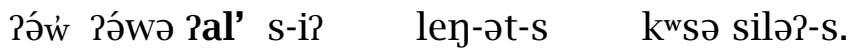

LNK NEG PAL' IRR-PRT see-TR-3.SBJ DET grandparent-3SG.POSS

'He didn't even see his grandparents.'

Shank describes both affirmative and negative clauses with ?al' as expressing three meaning components: (i) a claim of the prejacent's truth or falsity, respectively, (ii) a non-scalar exhaustive inference that all other alternatives are false, ${ }^{22}$ and (iii) a scalar inference that the prejacent is more likely than than its alternatives. Concretely, (48) suggests that (i) the speaker went to Victoria, (ii) didn't go anywhere else, and that (iii) Victoria was the most likely place to go; and (49) suggests that (i) he didn't see his grandparents, (ii) he didn't see anyone else, and (iii) his grandparents were the most likely people for him to see.

Shank argues that the prejacent claim (i) is (part of) the truth condition whereas that the scalar component (iii) is presupposed. Shank also describes the exhaustive inference (ii) in both affirmative and negative clauses as part of the truth condition, but as Guerzoni (2003: p. 202) notes, Shank does not provide evidence to support this claim over the alternative possibility that it is presuppositional. Based on this, Guerzoni suggests ?al' is a purely presuppositional operator that introduces both a scalar (most likely) inference and a non-scalar exhaustivity inference. ${ }^{23}$

We believe that the behavior of all examples of Samish ?al' as described in Shank 2003 are in fact compatible with our proposal for Burmese hmá. The prejacent being the most likely alternative and all other alternatives being false, as claimed by Shank and Guerzoni to be required by ral', would also satisfy the scalar exhaustive presupposition we propose for hmá in (16/34), that all less likely alternatives are false. A concrete test case that could tease apart these two descriptions would be to test whether the prejacent of ?al' is truly required to be the most likely alternative or not, as we tested for Burmese hmá in (31).

22 In portions of Shank's discussion, this is described as the negation of an at-issue existential requirement.

23 This meaning is also what she proposes for what she refers to as German nur $_{2}$ and Italian $\mathrm{solO}_{2}$, which appear as part of the particle combinations auch nur and anche solo. We refer the interested reader to Guerzoni 2003: ch. 4. 


\section{Focus concord and the effect of sentence-final $t a / d a$}

In this section we return to the interaction of the sentence-final mood marker $t a / d a$ with the interpretation of hmá. As we saw in Section 3, hmá in the presence of local negation may introduce (cleft) exhaustivity with scope over negation or lead to a scalar reading, akin to English scale-reversed even. In Section 4, we attributed this difference to a scope ambiguity between negation and hmá, which was further supported by the behavior of Blackfoot ikak in Section 5, where the relative scope of these ingredients is morphologically clear.

But as noted above, there is also another factor at play in distinguishing these two uses of hmá. In the basic Burmese examples considered in Section 3 - repeated in (51) and (52) - we observed that this choice of interpretation appears to correlate with the presence or absence of the sentence-final mood marker $t a / d a$. These facts are summarized in (50).

(50) Two interpretations for hmá with local negation, from Section 3:

\begin{tabular}{llll} 
& description & mood marker & LF \\
\cline { 2 - 3 } a. "scalar hmá" & (51) & ta/da & NEG > hmá (28) \\
b. "exhaustive hmá" > NEG & (52) & default (p'ù/bù) & hmá > NEG (24)
\end{tabular}

(51) Scalar hmá (NEG > hmá):

$$
=(8 \mathrm{a} / 26 \mathrm{a})
$$

Aun=gá $\quad$ ye=go=hmá mă-thauq-k'éh-da.

Aung $=$ NOM water $=$ ACC $=$ HMÁ NEG-drink-PST-DA

$\approx$ 'Aung didn't even drink WATER.'

$$
\text { Exhaustive hmá > NEG: } \quad=(10 / 22)
$$

$$
\begin{aligned}
& \text { Aun=gá ye=go=hmá mă-thauq-k'éh-bù. } \\
& \text { Aung=NOM water=ACC=HMÁ NEG-drink-PST-NEG } \\
& \approx \text { 'It's WATER that Aung didn't drink.' }
\end{aligned}
$$

In this section we clarify the relationship between sentence-final $t a / d a$ and the different uses of hmá and present an analysis of this interaction. In many simple discourses, the correlation summarized in (50) above indeed seems to hold, but we will also show that this correlation is dissociable in both directions, in particular discourse contexts. 
A variably exhaustive and scalar focus particle in Burmese

\subsection{Focus concord}

One way to describe the frequent correlation summarized above in (50) is as a dependency between scalar hmá and sentence-final $t a / d a$. Very similar dependencies have been described in the literature under the banner of focus concord, where the use of a particular focus particle necessitates a particular inflection on the containing clause's verb.

A well studied case is focus concord in Sinhala (Indo-Aryan): verbs have two endings, the descriptively "neutral" - $a$-final form and the - $e$-final form which appears when one of a certain set of focus particles is present and takes scope over the clause (Kishimoto 2005, 2018, Hagstrom 1998, Slade 2011, 2018, and references there). Consider the contrast between the basic Sinhala sentence in (53a), which ends with an - $a$-final form verb (glossed “A”), versus (53b) with narrow (cleft) focus on the object with the optional particle $y,{ }^{24}$ which triggers the $-e$-final verb form ("E”).

(53) Focus concord in Modern Colloquial Sinhala: (Slade 2018: p. 3)
a. Mamə $\overline{\mathrm{e}}$ potə kiyewwa.
b. Mamə $\bar{e} \quad$ potə $(=\mathbf{y})$ kiyewwe. I.NOM that book read.A I.NOM that book $=$ Y read.E 'I read that book.' 'It was that book that I read.'

Another well studied example is focus concord in Old Japanese, which is termed kakari-musubi in the Japanese literature (Whitman 1997, Hagstrom 1998, Watanabe 2002, Yanagida 2006, Aldridge 2018, Narrog 2019, and references there). Regular finite clauses end with a form known as "conclusive" (Japanese shuushi; ss) as in (54a), but the use of certain focus particles such as zo trigger the use of the adnominal verb ending (rentai; RT) as in (54b). ${ }^{25}$

(54) Focus concord in Old Japanese:

(Hendricks 2000: pp. 156-157)
a. Yuki siro-si.
b. Yuki=zo siro-ki.
snow white-ss snow $=$ ZO white-RT
'The snow is white.'
'It is the snow which is white.'

In both Sinhala and Old Japanese, there is a connection between the verb form triggered by focus concord and that which appears in relativized or

24 We assume that a covert version of $y$ is present for cleft focus in (53b), even if it is not pronounced.

25 In glossing these forms as -SS and -RT, we follow Aldridge 2018. Another focus particle, koso, requires the use of yet another ending, known as izen "realis" inflection. 
nominalized clauses. The -e-final verb form required by focus constructions in Sinhala historically derives from clausal nominalizations, although it does not synchronically have such functions (Slade 2011: ch. 11). In Old Japanese, the verb form triggered by zo and other focus particles as in $(54 \mathrm{~b})$ is the adnominal (rentai) form, so called as it is also used in relative clauses. ${ }^{26}$

This same connection is observed in the Burmese pattern studied here. Recall from Section 2 that the mood marker which frequently cooccurs with the scalar use of $h m a ́$ is $t a / d a$, which is also the verb form in headless relative clauses and clausal nominalizations. Although not conclusive, this parallel further motivates the discussion of the Burmese hmá facts in relation to the existing literature on focus concord.

We can imagine broadly two modes of explanation for such focus concord phenomena. The first is that this correlation is enforced in the morphosyntax. Focus particles enter into a morphosyntactic dependency with a high, clausal head, requiring a particular verbal inflection to be realized. This is in fact the dominant approach to focus concord phenomena - see for example Kishimoto 2005, 2018, Hagstrom 1998, Slade 2011 for Modern Colloquial Sinhala and Ikawa 1998, Watanabe 2002, Kuroda 2007, Aldridge 2018 for Old Japanese - although individual accounts vary as to the specific type of morphosyntactic dependency involved: for example, an Agree relationship, (covert) movement, or other. Specifically for the behavior of Burmese hmá, where we have argued above for a unified analysis for exhaustive and scalar hmá, a syntactic account might take the following form: The presence of hmá scoping under negation triggers or correlates with the presence of $t a / d a$, whereas the non-ta/da default mood marker is used otherwise.

The second type of account for such a focus concord effect is more indirect, based on the independent semantics/pragmatics associated with the choice of verbal inflection. Suppose that particular semantic or pragmatic functions can be attributed to the different verbal inflections involved in a focus concord interaction. If the use of particular focus particles is compatible with the meaning of some verbal inflection options but not others, we may be able to derive the focus concord effect as a semantic or pragmatic

26 There are, however, other cases of focus concord where the focus-related verb form has no known diachronic or synchronic connection to nominalization. For example, focus concord is attested in a number of Northern Ryukyuan (Japonic) languages, but with focus constructions triggering a dedicated verb form independent of nominalizing inflection; see for example Shimoji 2018 and citations there. 
A variably exhaustive and scalar focus particle in Burmese

epiphenomenon. This is precisely the type of approach we argue for in the next section for the relationship between hmá and $t a / d a$ in Burmese.

We are aware of just one previous work arguing for such an approach to focus concord phenomena. Shimoji (2009, 2011) describes an interaction in the Irabu dialect of Miyako Ryukyuan (Japonic > Southern Ryukyuan) which he calls "quasi-kakari-musubi". ${ }^{27}$ Past tense verbs come in two mood variants, one which is morphologically unmarked (55a) and an - $m$-final form that Shimoji 2011 calls "realis" (REAL) (55b). When the focus particle $d u$ is used, a past tense clause must show unmarked inflection:

(55) Verb inflection options in Irabu past tense clauses with $d u$ :

(Shimoji 2011: p. 120)
a. $\quad \mathrm{Ba}=\mathrm{a} \quad$ kuruma $=\mathrm{u}=\mathbf{d u} \mathbf{v v}$-tar. $1 \mathrm{SG}=\mathrm{TOP}$ car $=\mathrm{ACC}=\mathrm{DU}$ sell-ASP 'I sold a car.'

b. *...vv-ta-m. sell-ASP-REAL

At first glance, this appears to be a focus concord pattern of the familiar sort, as in Modern Colloquial Sinhala and Old Japanese: the use of a particular focus particle $(d u)$ appears to necessitate the use of a particular verbal inflection. Furthermore, the morphologically unmarked form as in (55a) is also the adnominal form used in relative clauses (Shimoji 2011: p. 117), strengthening the parallel to these other patterns above.

But Shimoji shows that the Irabu pattern is different from these other focus concord interactions in two important ways. First, when we look at nonpast clauses, which allow for four different final inflections - rather than the just two options, unmarked vs - $m$-final, in past tense clauses - we see that $d u$ does not necessitate the use of the unmarked ending in non-past clauses; the "irrealis intentional" (IRR.INT) and "irrealis optative" (IRR.OPT) inflections are also compatible with $d u$, although the - $m$-final "realis" form is again disallowed:

27 We thank Chris Davis (p.c.) for bringing Shimoji's work to our attention. In the Irabu data here and Scottish Gaelic data below, ASP = aspect. 
(56) Verb inflection options in Irabu non-past clauses with $d u$ :

(Shimoji 2011: pp. 120-121)
a. $\quad \mathrm{Ba}=\mathrm{a} \quad \mathrm{kuruma}=\mathrm{u}=\mathbf{d u} \mathrm{vv}-\varnothing$. $1 \mathrm{SG}=\mathrm{TOP}$ car $=\mathrm{ACC}=\mathrm{DU} \quad$ sell-NPST
'I sell a car.'
b. ...vv-di.
sell-IRR.INT
'I will (intend to) sell a car.'
c. ...vv-baa-i. sell-IRR.OPT-eh

'I want to sell a car.'

d. *...vv- $\varnothing-\mathbf{m}$.

sell-NPST-REAL

Shimoji argues that $d u$ is thus best described as disallowing cooccurrence with the - $m$-final realis form, rather than specifically requiring the unmarked form, leading to his description of the pattern as "quasi-kakari-musubi".

Second, main clauses in Irabu without any focus particle can use the unmarked or - $m$-final realis verbal inflection (see (55a,b)), with the latter expressing “(a) [the] speaker's perceived certainty, and (b) high information value, in that the speaker indicates that his message is new information to the hearer as the hearer does not know, or has a wrong assumption about, the truth of the proposition" (Shimoji 2011: p. 122). Shimoji argues that this is the key to the cooccurrence restriction with $d u$ : "since the realis form expresses new information to the hearer, it should never co-occur with a focus marker, since the predicate in a focus construction should be presupposed ... Thus it is this pragmatic feature of the realis form that leads to the exclusion of this form as the predicate form in the focus construction" (Shimoji 2011: p. 124). Setting the details of this interaction aside, the intuition behind Shimoji's analysis is clear: one particular verb form has a particular pragmatic requirement which, according to Shimoji, is incompatible with the use of the focus particle $d u$, explaining this particular focus concord pattern.

\subsection{Sentence-final $t a / d a$ as a marker of propositional clefts}

We now address the observed interaction between the different readings of Burmese hmá and sentence-final ta/da. Recall that in the basic data in Section 3, hmá in a negative clause with $t a / d a$ was interpreted as scalar (analyzed as NEG $>h m a ́$ ), whereas $h m a ́$ in a negative clause without ta/da was interpreted as exhaustive ( $h m a ́$ $>$ NEG). Although a correlation of this form holds across much of our data, we will also show that it can be dissociated in both directions, under particular discourse conditions.

We will therefore argue that this apparent correlation is due to the independent pragmatics associated with sentence-final $t a / d a$, rather than a strict 
A variably exhaustive and scalar focus particle in Burmese

morphosyntactic dependency, similar to Shimoji's analysis for "quasi" focus concord in Irabu. Specifically, we will argue that $t a / d a$ marks main clauses as propositional clefts (PC) in the sense of Sheil 2016, which are utterances that have a particular status in the organization of the discourse. Clauses with scalar hmá often - but not always - have the status of PCs, and thereby exhibit the $t a / d a$ mood marker, whereas clauses with exhaustive hmá are rarely - but again not never - ta/da-marked PCs.

We first introduce the notion of propositional cleft (PC) as developed in Sheil 2016. For comparison, consider first the canonical cleft in Scottish Gaelic in (57). The structure opens with a copular verb 's and a pronoun (here, ann, translated as 'in him/it') followed by the focused pivot constituent and a gapped clause. For these constructions, Sheil adopts the semantics for English it-clefts developed in Velleman et al. 2012.

(57) Scottish Gaelic cleft: (Adger 2011: p. 1, repeated in Sheil 2016: p. 81)

'S ann [pivot do Mhàiri] [CP a thug Calum an cat__ ]. COP in.3SGM to Mary C.REL give.ASP Calum the cat

'It's to Mary that Calum gave the cat.'

Propositional clefts in Scottish Gaelic such as in (58) share the same morphosyntactic ingredients as in clefts such as (57) but notably do not have any pivot constituent separated from the rest of the embedded clause. ${ }^{28}$

(58) Scottish Gaelic propositional cleft:

(Sheil 2016: pp. 43-44)

Context: When they came, he had let the fields be eaten by the sheep.

A: By whom [i.e., whose authority] did you eat the fields?

B: It was not I that ate them at all.

'S ann [сP a dh'ith na caoraich eud]. COP in.3SGM C.REL eat.ASP the.PL sheep.PL 3PL

'The sheep ate them.' (PC)

Sheil argues that "the PC is licensed in a discourse where there is an unresolved or unaddressed question, and the PC functions in this context to revise the line of inquiry in the discourse, either providing an answer to the

28 Example (58) thus appears to literally be akin to 'It's that the sheep ate them.' This makes it tempting to relate PCs to the English it's that... construction, but Sheil (2016: pp. 5-7) shows that their ranges of use are distinct. We note that Kato (2020: pp. 579-581) offers English translations of the form 'It is the case that...' for $t a / d a$-final clauses in Burmese. 
unresolved or unaddressed question" (p. 31, emphasis ours), also indirectly signaling that the current line of inquiry will no longer be pursued.

This description is formalized using the notions of Questions Under Discussion (QUD) and discourse moves from Roberts 1996 and subsequent work. Again, consider example (58). The immediate QUD posed by speaker A in (58) is "By whose authority did you eat the fields?" This original line of inquiry presupposes a positive answer to an implicit question 'Did B eat the fields?' which speaker B first takes issue with. Then B utters the PC 'The sheep ate them.' The PC addresses the implicit super-question 'Who ate the fields?'. The resulting organization of this discourse is illustrated in discourse-tree (or d-tree; see Büring 2003, also Constant 2014, Rojas-Esponda 2014, Sheil 2016) form in (59). Questions in the d-tree end with ? and implicit moves are in parentheses. B's response is split into individual moves, labeled $B_{1}$ and $B_{2}$.

(59) Final D-tree for (58):

(modified from Sheil 2016: p. 44)

New line of inquiry

(Who ate the fields?)

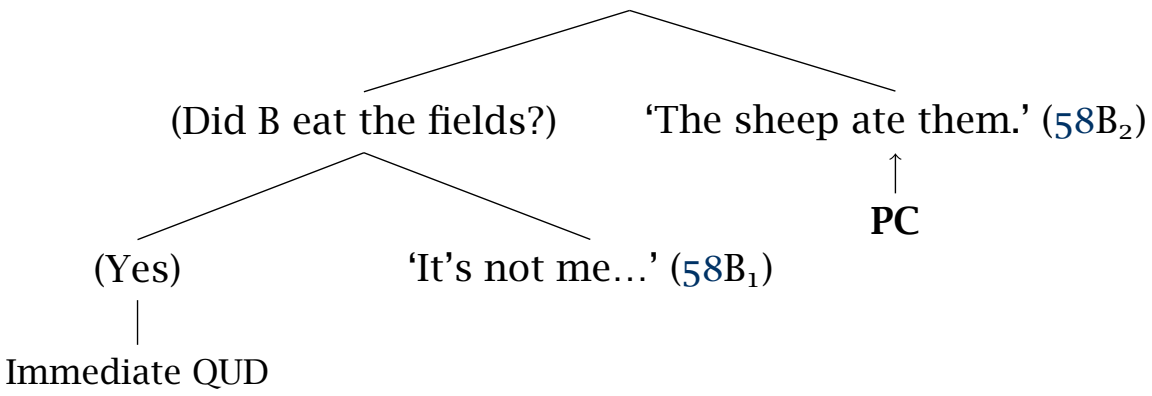

'By whose authority did

you eat the fields?' (58A)

Speaker B's second sentence, 'The sheep ate them', is a PC as it addresses a new, related question 'Who ate the fields?', revising the line of inquiry and signaling that the original QUD will not be addressed. See Sheil 2016 chapter 3 for detailed discussion of the discourse uses of PCs, as well as a proposed compositional semantics which derives these pragmatic effects from a general cleft semantics.

We argue that the Burmese mood marker $t a / d a$ marks a matrix clause as a PC. ${ }^{29}$ In previous work, Kato (1998: pp. 88-89) notes that utterances with ta/da are similar to Japanese -no-da PCs, and Simpson (2008: p. 281; p.c.)

29 In addition, recall that $t a / d a$ also appears as a nominalizing ending (6). We suspect that there is a historical connection here, as discussed for Burmese in Simpson 2008 and more 
A variably exhaustive and scalar focus particle in Burmese

notes that $t a / d a$ is similar to Mandarin Chinese shì...de PCs. Both Japanese -no-da and Mandarin shì..de are discussed as examples of PCs in Sheil 2016.

We motivate this proposal for $t a / d a$ through data on the (in)felicity of $\mathrm{ta} / \mathrm{da}$ for different types of discourse moves, for utterances without hmá. We first note that the use of $t a / d a$ is inappropriate for a direct answer to the immediate QUD, just as Sheil shows for PCs more generally. This is particularly clear with the explicit question in (6oA), which can be answered in (6oB) using the default mood marker (here, non-future teh/deh) but not with $t a / d a$. We note that there is some speaker variation on the use of teh/deh and $t a / d a$ in the following examples in (6o) and (61). We return to the details of this variation at the end of this section, and here first concentrate on the judgments of the majority of our speakers.

\section{(6o) $\mathrm{Ta} / \mathrm{da}$ is inappropriate for direct answers to questions:}

A: What did Suu drink?

B: Sú=gá $\quad$ ye=go thauq-k'éh- $\left\{{ }^{`}\right.$ deh/\#da $\}$.

Suu $=$ NOM water $=$ ACC drink-PST $-\left\{{ }^{`}\right.$ NFUT $/ \#$ DA $\}$

'Suu drank water.'

In (6o), 'What did Suu drink?' is the immediate QUD. A direct answer to this question does not license the use of the PC marker, $\mathrm{ta} / \mathrm{da}$.

In contrast, PCs are natural for raising a new line of inquiry in the process of correcting another speaker's belief, as we saw in the Scottish Gaelic example (58) above. The use of $t a / d a$ is also natural in the correction in (61). In such an utterance where it is licensed, its use of $t a / d a$ is judged as nearobligatory.

\section{(61) $\mathrm{Ta} / \mathrm{da}$ is appropriate for corrections:}

A: Suu drank beer.

B: Mă-houq-p'ù, Sú=gá ye=go thauq-k'éh- $\left\{\#\right.$ deh $/{ }^{\vee}$ da $\}$. NEG-right-NEG Suu $=$ NOM water $=$ ACC drink-PST- $\left\{\#\right.$ NFUT $\left./{ }^{`} \mathrm{DA}\right\}$

'No, Suu drank water.'

Here, speaker A begins by addressing the implicit polar question 'Did Suu drink beer?'. Speaker B addresses this immediate QUD with a contrasting answer, 'No', and then asserts that 'Suu drank water' instead. This assertion

generally for propositional clefts in other languages in Sheil 2016, but we will not discuss the synchronic or diachronic syntax of $t a / d a$ PCs here. 
is not an answer to the original immediate QUD, but instead addresses an (implicit) sister question, 'Did Suu drink water?'. These two questions are sister questions in that they are both natural sub-questions of the implicit super-question 'What did Suu drink?', as reflected in the d-tree in (62):

\section{D-tree for (61):}

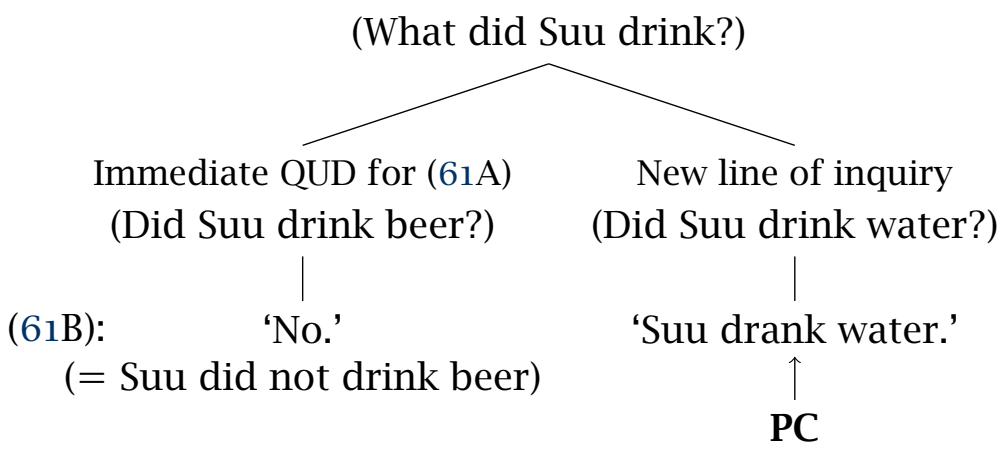

B's shift to this new line of inquiry makes the assertion that Suu drank water here a PC and thus marked by $t a / d a$. In contrast, the same assertion that Suu drank water in (6o) above, where it addresses the immediate QUD, does not count as a PC and $t a / d a$ is not used.

As noted in passing above, we have observed some speaker variation in (6o) and (61). Four out of five of the speakers we consulted agree on the judgments we report above: they find a clear contrast in acceptability between $t e h / d e h$ and $t a / d a$ in the respective contexts, in the direction that we report. One of the five speakers, however, found that both endings are possible in both examples. An anonymous reviewer also reports a judgment similar to this last speaker. Here, we concentrate on the clear and internally consistent judgments shared by the majority of the speakers we have worked with, and leave a better understanding of the source of this variation for future work.

\subsection{Pragmatic focus concord in Burmese}

With this proposal for $t a / d a$ as PC-marking in place, we return to the interaction between the interpretations of hmá and the use of $t a / d a$, summarized in (50) above. We argue that the consideration of the semantics of hmá in concert with the PC pragmatics of $t a / d a$ can explain their apparent focusconcord-like correlation, as well as its exceptions which we present below. 
A variably exhaustive and scalar focus particle in Burmese

We consider first the scalar use, which we have analyzed as the effect of hmá scoping under negation: NEG > hmá. Our canonical example is repeated again in (63), together with the LF we propose for it.

(63) Scalar hmá with $t a / d a$ :

$$
=(8 \mathrm{a} / 26 \mathrm{a} / 51)
$$

Aun=gá $\quad$ ye=go=hmá mă-thauq-k'éh-da.

Aung $=$ NOM water $=$ ACC $=$ HMÁ NEG-drink-PST-DA

$\approx$ 'Aung didn't even drink WATER.'

(64) LF for scalar hmá: $\quad=(28)$

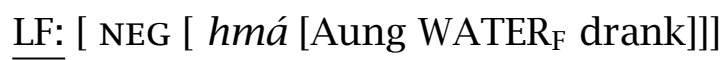

We argue that the semantics of scalar hmá, derived from (64), makes it natural to use as a PC, explaining its frequent appearance with the sentencefinal $\mathrm{ta} / \mathrm{da}$ mood marker, as in (63). Let's consider what type of discourse context supports the felicitous use of scalar hmá, and when and why a speaker might choose to utter this sentence.

The association of hmá (within the scope of negation) with 'water', as in (64), requires the existence of alternative propositions to the prejacent 'that Aung drank water.' These propositions together constitute the wh-question, 'What did Aung drink?'. Consider a discourse where 'What did Aung drink?' is under discussion. The at-issue content of (63) is that Aung didn't drink water. This negative proposition is not a congruent possible answer to the wh-question 'What did Aung drink?', but it can function as an answer to the polar question 'Did Aung drink water?', which is a sub-question of the whquestion. This is illustrated in (65) below.

(65) Sample d-tree for scalar hmá (63):

What did Aung drink?

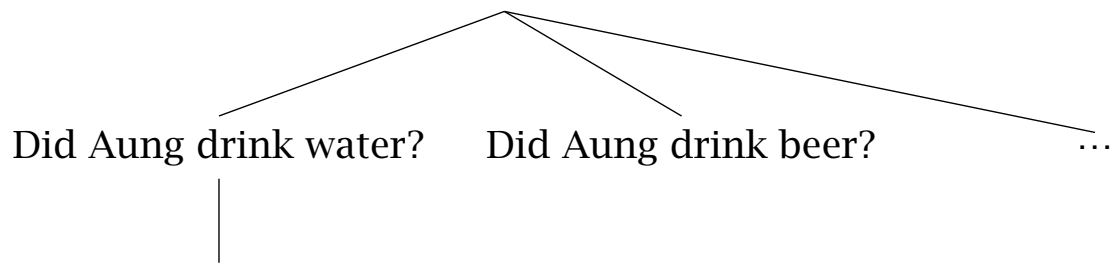

‘Aung didn’t drink HMÁ water.' (63)

But the utterance of (63) in a discourse with the structure in (65) does much more than simply resolve a single sub-question ('Did Aung drink water?') in the negative. Recall that hmá presupposes that all less likely alternative 
propositions are false (16/34). The use of hmá thus signals that other sister questions of the form 'Did Aung drink beer?' associated with less likely propositions must also be resolved in the negative, together partially or fully resolving the super-question 'What did Aung drink?' as well. ${ }^{30}$

We argue that this dual function of utterances with scalar hmá-addressing a specific sub-question, while also indirectly addressing a superordinate question related through its focus alternatives - helps to explain their use in discourse and the fact that such utterances are often PCs. Consider a context where the super-question 'What did Aung drink?' is under discussion and the speaker believes that Aung didn't drink anything, or at least didn't drink much. Choosing a likely proposition among the possible alternatives (here, 'Aung drank water') and answering the associated polar question in the negative with scalar hmá is an efficient way for the speaker to signal their stance on the entire super-question. If the sub-question they choose to address in order to make this point - here, 'Did Aung drink water?' - has not yet been raised in the discourse, it is a "new line of inquiry" in Sheil's terms, making the utterance a PC and thus receiving ta/da marking as in (63).

The scalar hmá example with sentence-final ta/da in (63) is natural in response to another speaker raising the super-question by uttering 'I wonder what Aung drank'; see (66a). It is also natural in a discourse such as (66b), where another speaker raises a sister-question such as 'Did Aung drink beer?'. Speaker B in (66b) answers this immediate QUD in the negative and then additionally comments on the implicit super-question 'What did Aung drink?' by applying scalar hmá to the more likely alternative 'water.' In both of these cases in $(66 a, b)$, the speaker is moving to a "new line of inquiry" by addressing 'water', making these scalar hmá utterances PCs and thus explaining their use of $t a / d a$.

(66) Preceding discourses for scalar hmá with ta/da (63):

a. A: I wonder what Aung drank.

B: ${ }^{\vee}(63)$

30 Whether or not (63) resolves the question 'Did Aung drink anything?' or not depends on the discourse context. If the prejacent is the most likely alternative - such as in the water vs beer scenario above (7) - hmá in (63) will require that Aung did not drink anything. But if the prejacent is not the most likely alternative - as in the water vs tea vs beer example in (31) - it will partially but not fully resolve the super-question. 
A variably exhaustive and scalar focus particle in Burmese

b. A: Did Aung drink beer?

$\mathrm{A}^{\prime}$ : (I think) Aung drank beer.

B: ' $N o,(63)$

C. A: Did Aung drink water?

B: \#(No,) (63)

(63) with sentence-final $t a / d a$ is however infelicitous in (66c), as a direct answer to 'Did Aung drink water?'. We argue that this is specifically because of the choice of sentence-final $t a / d a$, as PCs are infelicitous as direct answers to questions; see for example (6o) above. ${ }^{31,32}$

It is, however, also possible to set up a discourse which supports the use of scalar hmá to comment on a super-question where the addressed subquestion is not a new line of inquiry, but in this case the use of $t a / d a$ is optional. The discourse in (67) is one such example. We can be sure that this is not an instance of exhaustive hmá with hmá taking scope over negation; if it were, it would be claiming that water is the only thing that Aung didn't drink, which is incompatible with the context and continuation.

(67) Scalar hmá without ta/da: ${ }^{33}$

A: I know that there was only beer and water at the party. Did Aung drink beer?

B: No, Aung didn't drink beer.

A: Then, did Aung drink water?

B: Aun=gá $\quad$ ye=go=hmá mă-thauq-k'éh-\{`bù $/{ }^{`}$ da $\}$.

Aung $=$ NOM water $=$ ACC $=$ HMÁ NEG-drink-PST- $\left\{{ }^{`}\right.$ NEG $\left./{ }^{`} \mathrm{DA}\right\}$

Thu=gá ba=hmá mă-thauq-k'éh-bù.

3=NOM what=HMÁ NEG-drink-PST-NEG

$\approx$ 'Aung didn't even drink water. He didn't drink anything.'

31 As noted above, there appears to be some variation on the strength of this effect. Notably, our one speaker who accepted $t a / d a$ in a direct answer to a wh-question in (6o) above also finds (66c) acceptable.

32 As an aside, we note that, in our judgment, the English sentence Aung didn't even drink WATER with scale-reversed even also follows the pattern of felicity in (66). We leave open why this English sentence, which does not have grammaticalized PC morphology, is also infelicitous as a direct answer as in (66c).

33 Although all data we report generally reflect the judgments of (at least) our five primary speakers, as we noted in Section 1 above, for this judgment one of our primary speakers was unavailable. The judgment here thus reflects the consistent judgment of the four speakers that we asked. 
Speaker B's utterance with scalar hmá simultaneously answers the immediate QUD posed by speaker A and resolves the implicit super-question 'What did Aung drink?' with the answer that Aung did not drink anything. ${ }^{34}$

Example (67) shows that scalar hmá can be felicitously used without a sentence-final $t a / d a$, supporting our proposal that the frequent cooccurrance of scalar hmá and sentence-final $t a / d a$ is due to their independent pragmatic functions. ${ }^{35}$ Sentences with scalar hmá are often PCs, receiving $t a / d a-$ marking, as they are often used to address a superordinate question by picking out a likely alternative and highlighting that even this likely alternative is false.

We now consider the pragmatic function of exhaustive hmá, such as in negative clauses with hmá scoping over negation. Our canonical example from above is repeated here as (68). In all of the examples considered thus far, negative clauses with exhaustive hmá have ended with the default negative mood marker $p$ 'ù/bù in place of $t a / d a$ and thus not as a PC.

\section{Exhaustive hmá with negation:}

$$
=(10 / 22 / 52)
$$

Aun=gá $\quad$ ye=go=hmá mă-thauq-k'éh-bù.

Aung $=$ NOM water $=$ ACC $=$ HMÁ NEG-drink-PST-NEG

$\approx$ 'It's water that Aung didn't drink.'

(69) LF for exhaustive hmá with negation: $\quad=(24)$

LF: [ hmá [ NEG [Aung WATER drank]]]

Recall that our proposal for the semantics of hmá (16/34) mirrors the proposal for the semantics of English it-clefts from Velleman et al. 2012, and it naturally follows its pragmatic function as well. Velleman et al. argue that a central property of clefts is that they address and fully resolve an existing QUD. A natural context for the use of (68) is a discourse with the immediate QUD 'What didn't Aung drink?'. The utterance of (68) offers an exhaustive answer to this QUD, terminating this existing line of inquiry. As no new lines

34 Formally, this may constitute a rejection of the question and its presuppositions (e.g., that at least one of the propositions in its Hamblin set denotation is true) or its revision (see e.g., Beaver \& Clark 2008: p. 36 and footnote 27 there), or it may count as an answer as it is sufficient for determining the truth or falsity of the Hamblin alternatives (i.e., all false). See Roberts 1996: pp. 11-12 for discussion of the latter view.

35 The $t a / d a$ mood marker is however also possible in the target scalar hmá sentence in (67). We tentatively suggest that this optionality may reflect a possibility for B's reply with $t a / d a$ to reflect the status of A's question 'Did Aung drink water?' as being a new line of inquiry, rather than B's own utterance to raise a new line of inquiry. 
A variably exhaustive and scalar focus particle in Burmese

of inquiry are raised via this discourse move, (68) is not a PC and thus resists the use of $t a / d a$.

However, exhaustive hmá with scope over negation - that is, the LF in (69) - can in fact be used with sentence-final ta/da if the discourse independently supports the utterance's status as a PC. One such example is in (70) below. Here, speaker A claims that Aung didn't drink beer. Speaker B disagrees with this claim with 'No' and then asserts that 'It's water that Aung didn't drink' with exhaustive hmá taking scope over negation:

\section{(70) Exhaustive hmá with negation, with ta/da:}

A: Aung didn't drink beer.

B: Mă-houq-p’ù, Aun=gá ye=go=hmá mă-thauq-k'éh-da. NEG-right-NEG Aung $=$ NOM water $=$ ACC $=$ HMÁ NEG-drink-PST-DA $\approx$ 'No, it's WATER that Aung didn't drink.' exhaustive $>$ NEG

Our proposal explains the use of $t a / d a$ in $(7 \mathrm{OB})$. The relevant discourse moves in (70) are illustrated in the d-tree in (71) below. We start with A's statement, which addresses the implicit polar question 'Did Aung not drink beer?'. Speaker B addresses this immediate QUD with 'No', and then shifts to a new line of inquiry: 'What did Aung not drink?', which is a super-question of the original immediate QUD. Using hmá, B gives an exhaustive answer to this super-question: 'It's water that Aung didn't drink.'

\section{(71) D-tree for (70):}

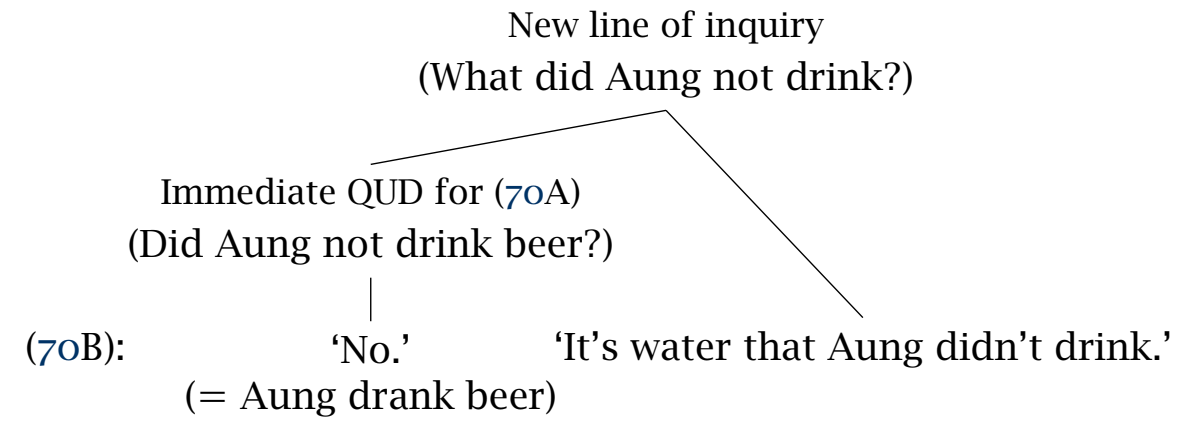

As this exhaustive hmá utterance addresses a new line of inquiry, it is a PC and thus takes the sentence-final mood marker $t a / d a$, as seen in (7o).

The examples of negative clauses with hmá discussed in this section are summarized together in (72) below. Earlier, in Section 3, we observed that scalar hmá tends to cooccur with sentence-final $t a / d a$ whereas exhaustive 
hmá occurs in negative clauses without ta/da. We have seen that this correlation is dissociable in both directions by manipulating the discourse context.

(72) Negative clauses with hmá:

\begin{tabular}{lcc}
\hline & $\begin{array}{c}\text { "Scalar hmá" } \\
(\mathrm{NEG}>h m a ́)\end{array}$ & $\begin{array}{c}\text { "Exhaustive } h m a ́ ">\text { negation } \\
(\text { hmá }>\text { NEG })\end{array}$ \\
\hline PC $(t a / d a)$ & $(66 \mathrm{a}, \mathrm{b})$ & $(70)$ \\
Non-PC $(* t a / d a)$ & $(67)$ & $(68)$ \\
\hline
\end{tabular}

Our proposal for the semantics of hmá and our analysis of $t a / d a$ as a marker of propositional clefts (Sheil 2016) together serve to explain these patterns of cooccurrence - why scalar hmá (hmá under the scope of negation) commonly cooccurs with $t a / d a$ and why exhaustive hmá (including hmá over negation) commonly appears without $t a / d a$ - as well as their exceptions. In contrast, a morphosyntactic agreement approach to the relationship between scalar hmá and sentence-final $t a / d a$, following much previous work on focus concord reviewed in Section 6.1 above, would have difficulty accounting for these principled exceptions.

Both scope possibilities must be available for negation and hmá as proposed in Section 4, independent of the choice of sentence-final marking, with the proper interpretation of such utterances then determined by the context. There is no dependency in either direction between the scope of hmá with respect to negation and the presence or absence of $t a / d a$.

\section{Conclusion}

In this paper we investigated the semantics of the Burmese focus particle hmá. Descriptively, hmá appears to have two distinct uses, as an exhaustive particle or a scalar particle, with Okell 1969: pp. 284-286 offering both English 'only' and 'even' as translations. We described the distribution of these two apparently distinct uses and offered a uniform analysis for hmá as a not-at-issue scalar exhaustive, similar to the analysis of cleft semantics in Velleman et al. 2012. On the surface, hmá is a constituent focus particle that encliticizes to a focus-containing phrase but takes propositional scope at LF. The scale-sensitive use of hmá comes about when hmá scopes under negation, whereas hmá taking widest scope leads to exhaustive, cleft semantics.

Burmese hmá shows that a common core may underlie descriptively "exhaustive" particles, translated as a cleft or only, and descriptively "scalar" 
A variably exhaustive and scalar focus particle in Burmese

particles which might be translated with English even. We suggested in Section 5 that such an analysis may extend to other variably exhaustive and scalar focus particles in other languages as well. Data from Blackfoot ikak from Bliss 2013 is particularly suggestive, showing that the choice of exhaustive versus scalar readings correlate with the particle's scope with respect to negation. At the same time, we have noted differences in the behavior of hmá with that of the distinct Burmese particles for 'only', p'èh/bèh, and 'even', taun/daun, highlighting lexicalized differences in the ordering of alternatives as one important source of variation between focus particle meanings.

We furthermore described and analyzed a focus-concord-like effect between scalar hmá and the sentence-final mood marker $t a / d a$. Following previous descriptions, we analyze $t a / d a$ as a marker for propositional clefts (PC), which reflect a discourse move where a new line of inquiry is addressed (Sheil 2016). We argue that the semantics of scalar hmá explains its pragmatic function of commenting on a super-question by explicitly addressing a particular sub-question. Scalar hmá in such cases will frequently - though not always - be a PC. On the other hand, exhaustive hmá naturally identifies a complete answer to a question, making it often - though not always address an existing QUD, and thus not a PC. We argue that this pragmatic account is superior to potential accounts in terms of morphosyntactic agreement, explaining the principled exceptions to the correlation, as well as offering a deeper explanation for the effect. We hope that our discussion, together with Shimoji's prior work on Irabu, might offer a template for further semantic/pragmatic explanations to focus concord phenomena in other languages, where accounts involving morphosyntactic agreement have been the norm.

Finally, we note that there is one additional use of hmá which we have not discussed here. hmá is used in combination with weak quantificational elements such as the numeral 'one'36 and wh-phrases to form negative polarity items (NPIs):

(73) ‘One’-hmá NPI:

(Okell 1969: p. 288)

Tă-yauq=néh=hmá mă-twé-bù-bù.

one-person=with=HMÁ NEG-meet-ever-NEG

'(We) have never met any (of them).'

36 See also Erlewine \& Lim 2020 and Lim \& Erlewine To appear for recent discussion of the numeral 'one' in Burmese. 


\section{(74) Wh-hmá NPI:}

Nga=gá beh-pàndhì=go=hmá mă-yu-géh-bù. $1=$ NOM which-apple $=$ ACC $=$ HMÁ NEG-take-PST-NEG

'I didn't take any apple(s).'

The connection between scalar particles and NPIs - in particular, those involving indefinites and wh-phrases - has been documented and studied in a range of previous work (Lee \& Horn 1995, Lahiri 1998, Erlewine \& Kotek 2016, a.o.). In particular, Erlewine (2019, in progress) develops a compositional analysis for these Burmese wh-hmá NPIs, based on the scalar exhaustive semantics for hmá established here.

\section{References}

Adger, David. 2011. Clefted situations: A note on expletives in Scottish Gaelic clefts. In Andrew Carnie (ed.), Formal approaches to Celtic linguistics, 316. Newcastle upon Tyne: Cambridge Scholars.

Aldridge, Edith. 2018. C-T inheritance and the left periphery in Old Japanese. Glossa 3(26). 1-22. https://doi.org/10.5334/gjgl.254.

Alxatib, Sam. 2020. Focus, evaluativity, and antonomy: A study in the semantics of only and its interaction with gradable antonyms (Studies in Linguistics and Philosophy (SLAP) 104). Cham, Switzerland: Springer. https: //doi.org/10.1007/978-3-030-37806-6.

Bajaj, Vandana. 2016. Scaling up exclusive -hii. New Brunswick, NJ: Rutgers University dissertation. https://doi.org/10.7282/T34170C8.

Beaver, David Ian \& Brady Clark. 2008. Sense and sensitivity: How focus determines meaning. West Sussex, UK: Wiley-Blackwell. https://doi.org/10 .1002/9781444304176.

Bhatt, Rajesh. 1994. The semantics of hi. Manuscript, University of Pennsylvania.

Bliss, Heather. 2010. Blackfoot -ikak: A case study of only and even. Presented at the Meeting of Semanticists Active in Canada (MOSAIC) 2 at McGill University.

Bliss, Heather. 2013. The Blackfoot configurationality conspiracy: Parallels and differences in clausal and nominal structures. Vancouver: The University of British Columbia dissertation. https://doi.org/10.14288/1.016 5708. 
A variably exhaustive and scalar focus particle in Burmese

Branan, Kenyon \& Michael Yoshitaka Erlewine. 2022. Anti-pied-piping. Manuscript, National University of Singapore. https://ling.auf.net/lingbuzz/o O5351/.

Büring, Daniel. 2003. On D-trees, beans, and B-accents. Linguistics and Philosophy 26(5). 511-545. https://doi.org/10.1023/A:1025887707652.

Büring, Daniel \& Manuel Križ. 2013. It's that, and that's it! Exhaustivity and homogeneity presuppositions in clefts (and definites). Semantics \& Pragmatics 6(6). 1-29. https://doi.org/10.3765/sp.6.6.

Constant, Noah. 2014. Contrastive topic: Meanings and realizations. Amherst, MA: University of Massachusetts Amherst dissertation. https://doi.org/1 0.7275/5694973.0.

Coppock, Elizabeth \& David Ian Beaver. 2011. Sole sisters. Semantics and Linguistic Theory (SALT) 21. 197-217. https://doi.org/10.3765/salt.v21io.261 5 .

Coppock, Elizabeth \& David Ian Beaver. 2014. Principles of the exclusive muddle. Journal of Semantics 31(3). 371-432. https://doi.org/10.1093/jos/fft 007.

Crnič, Luka. 2011a. Getting even. Cambridge, MA: Massachusetts Institute of Technology dissertation. http://hdl.handle.net/1721.1/68912.

Crnič, Luka. 2011b. On the meaning and distribution of concessive scalar particles. North East Linguistic Society (NELS) 41(1). 143-156. https://luka crnic.com/pdfs/nels41.pdf.

DeLancey, Scott. 2011. Finite structures from clausal nominalization in TibetoBurman. In Foong Ha Yap, Karen Grunow-Hårsta \& Janick Wrona (eds.), Nominalizations in Asian languages: Diachronic and typological perspectives, 343-359. John Benjamins. https://doi.org/10.1075/tsl.96.

Deo, Ashwini. 2014. Marathi $=c$ : Identifying the strongest true alternative. Presented at Formal Approaches to South Asian Languages (FASAL) 4 .

Deo, Ashwini. 2020. The strongest assertable alternative: Marathi $=c$ and its Indo-Aryan counterparts. Presented at Semantics and Linguistic Theory (SALT) 30. https://osf.io/xdqv7/.

Erlewine, Michael Yoshitaka. 2018. Even doesn't move but associates into traces: A reply to Nakanishi 2012. Natural Language Semantics 26(3-4). 167-191. https://doi.org/10.1007/s11050-018-9142-6.

Erlewine, Michael Yoshitaka. 2019. Wh-quantification in Alternative Semantics. Presented at GLOW in Asia XII, Dongguk University, Seoul. https://m itcho.com/research/talk-glowinasia2019.html. 
Erlewine, Michael Yoshitaka \& Hadas Kotek. 2016. Even-NPIs in Dharamsala Tibetan. Linguistic Analysis 40(3-4). 129-165.

Erlewine, Michael Yoshitaka \& Meghan Lim. 2020. Anti-uniqueness without articles. Semantics and Linguistic Theory (SALT) 30. 430-449. https://do i.org/10.3765/salt.v30io.4848.

Giannakidou, Anastasia. 2007. The landscape of EVEN. Natural Language \& Linguistic Theory 25(1). 39-81. https://doi.org/10.1007/s11049-0o6-900 6-5.

Greenberg, Yael. 2016. A novel problem for the likelihood-based semantics of even. Semantics \& Pragmatics 9(2). 1-28. https://doi.org/10.3765/sp.9.2.

Guerzoni, Elena. 2003. Why even ask? On the pragmatics of questions and the semantics of answers. Cambridge, MA: Massachusetts Institute of Technology dissertation. http://hdl.handle.net/1721.1/17646.

Hagstrom, Paul. 1998. Decomposing questions. Cambridge, MA: Massachusetts Institute of Technology dissertation. http://hdl.handle.net/1721.1/9649.

Hendricks, Peter. 2000. Kakari particles and the merger of the predicative and attributive forms in Old Japanese. In John Charles Smith \& Delia Bentley (eds.), Historical linguistics 1995: Volume 1: General issues and nonGermanic languages (Current Issues in Linguistic Theory 161), 155-167. Amsterdam \& Philadelphia: John Benjamins. https://doi.org/10.1075/cilt .161.11hen.

Herburger, Elena. 2000. What counts: Focus and quantification (Linguistic Inquiry Monographs 36). MIT Press. https://doi.org/10.7551/mitpress/720 1.001.0001.

Horn, Laurence R. 1969. A presuppositional analysis of only and even. Chicago Linguistic Society (CLS) 5. 98-107.

Horn, Laurence R. 1989. A natural history of negation (The David Hume series). Chicago, IL: University of Chicago Press.

Ikawa, Hajime. 1998. On kakarimusubi in Old Japanese: A possibility under a perspective of generative grammar. Journal of Japanese Linguistics 16(1). 1-38. https://doi.org/10.1515/jjl-1998-0103.

Jenny, Mathias \& San San Hnin Tun. 2016. Burmese: A comprehensive grammar. London: Routledge. https://doi.org/10.4324/9781315651194.

Karttunen, Lauri \& Stanley Peters. 1979. Conventional implicature. In ChoonKyu Oh \& David A. Dinneen (eds.), Presupposition (Syntax and Semantics 11), 1-56. Academic Press. https://doi.org/10.1163/9789004368880_002.

Kato, Atsuhiko. 1998. Ekusupuresu Birumago [Express Burmese]. Tokyo: Hakusuisha. 
A variably exhaustive and scalar focus particle in Burmese

Kato, Atsuhiko. 2020. Burmese. In Tasaku Tsunoda (ed.), Mermaid construction: A compound-predicate construction with biclausal appearance (Comparative Handbooks of Linguistics (CHL) 6), 557-604. Berlin \& Boston: De Gruyter Mouton. https://doi.org/10.1515/9783110670844.

Kay, Paul. 1990. Even. Linguistics and Philosophy 13(1). 59-111. https://doi.or g/10.1007/BFoo630517.

Kishimoto, Hideki. 2005. Wh-in-situ and movement in Sinhala questions. Natural Language \& Linguistic Theory 23(1). 1-51. https://doi.org/10.1007/s 11049-004-6574-0.

Kishimoto, Hideki. 2018. Sinhala focus concord constructions from a discourse-syntactic perspective. Glossa 3(9). 1-25. https://doi.org/10.5334/g jgl.26o.

König, Ekkehard. 1991. The meaning of focus particles: A comparative perspective. London: Routledge.

Križ, Manuel. 2017. Referentiality, exhaustivity, and trivalence in it-clefts. Manuscript, Institut Jean-Nicod. https://semanticsarchive.net/Archive /TVjNDUoM/Kriz\%2O2017\%20Clefts.pdf.

Kuroda, Sige-Yuki. 2007. On the syntax of Old Japanese. In Bjarke Frellesvig, Masayoshi Shibatani \& John Charles Smith (eds.), Current issues in the history and structure of Japanese, 264-317. Tokyo: Kurosio.

Lahiri, Utpal. 1998. Focus and negative polarity in Hindi. Natural Language Semantics 6(1). 57-123. https://doi.org/10.1023/A:1008211808250.

Lee, Young-Suk \& Laurence R. Horn. 1995. Any as indefinite plus even. Manuscript, Yale University.

Lim, Meghan \& Michael Yoshitaka Erlewine. To appear. Definiteness and indefiniteness in Burmese. TripleA 7. https://mitcho.com/research/burme se-indef.html.

Matthewson, Lisa. 2004. On the methodology of semantic fieldwork. International Journal of American Linguistics 70(4). 369-415. https://doi.org/10 $.1086 / 429207$.

Narrog, Heiko. 2019. Origin and structure of focus concord constructions in Old Japanese: A synthesis. Glossa 4(108). 1-41. https://doi.org/10.5334/g jgl.629.

New, Keely \& Michael Yoshitaka Erlewine. 2018. The expression of exhaustivity and scalarity in Burmese. Semantics and Linguistic Theory (SALT) 28. 271-288. https://doi.org/10.3765/salt.v28io.4442.

Okell, John. 1969. A reference grammar of Colloquial Burmese. London: Oxford University Press. 
Okell, John. 1994. Burmese: An introduction to the spoken language. DeKalb, IL: Northern Illinois University, Center for Southeast Asian Studies.

Okell, John. 2002. Burmese by ear. Audio-Forum, the School of Oriental \& African Studies.

Okell, John \& Anna Allott. 2001. Burmese/Myanmar dictionary of grammatical forms. Richmond: Curzon.

Renans, Agata \& Joseph P. De Veaugh-Geiss. 2019. Experimental studies on it-clefts and predicate interpretation. Semantics \& Pragmatics 12(11). htt ps://doi.org/10.3765/sp.12.11.

Roberts, Craige. 1996. Information structure in discourse: Towards an integrated formal theory of pragmatics. In Jae-Hak Yoon \& Andreas Kathol (eds.), Papers in semantics, vol. 49 (OSU Working Papers in Linguistics). Reprinted in Semantics \& Pragmatics 5(6), 1-69, 2012. https://doi.org/10 .3765 sp.5.6.

Rojas-Esponda, Tania. 2014. A discourse model for überhaupt. Semantics \& Pragmatics 7(1). 1-45. https://doi.org/10.3765/sp.7.1.

Romeo, Nicoletta. 2008. Aspect in Burmese: Meaning and function. Amsterdam: John Benjamins. https://doi.org/10.1075/slcs.96.

Rooth, Mats. 1985. Association with focus. Amherst, MA: University of Massachusetts, Amherst dissertation.

Rooth, Mats. 1992. A theory of focus interpretation. Natural Language Semantics 1(1). 75-116. https://doi.org/10.1007/BFo2342617.

Rullmann, Hotze. 1997. Even, polarity, and scope. In Martha Gibson, Grace Wiebe \& Gary Libben (eds.), Papers in experimental and theoretical linguistics 4, 40-64. Department of Linguistics, University of Alberta, Edmonton, Canada. https://www.semanticsarchive.net/Archive/WZhOWY5N/rullma nn1997.pdf.

Shank, Scott. 2003. Not even in Samish. Semantics of Under-Represented Languages in the Americas (SULA) 2. 157-173. https://scholarworks.umass.e $\mathrm{du} / \mathrm{sula} / \mathrm{vol} 2 / \mathrm{iss} 1 / 11$.

Sheil, Christine M. 2016. Scottish Gaelic clefts: Syntax, semantics, and pragmatics. Berkeley, CA: University of California, Berkeley dissertation. http s://escholarship.org/uc/item/8wp6o39b.

Shimoji, Michinori. 2009. Epistemic modality in Irabu Ryukyuan. In Language description papers of Tokyo Foreign Language University, vol. 5, 25-42. h ttp://hdl.handle.net/10108/90536.

Shimoji, Michinori. 2011. Quasi-Kakarimusubi in Irabu. Japanese/Korean Linguistics 18. 114-125. 
A variably exhaustive and scalar focus particle in Burmese

Shimoji, Michinori. 2018. Information structure, focus, and focus-marking hierarchies in Ryukyuan languages. Gengo Kenkyu 154. 85-121. https://d oi.org/10.11435/gengo.154.0_85.

Simpson, Andrew. 2008. The grammaticalization of clausal nominalizers in Burmese. In María José López-Couso \& Elena Seoane (eds.), Rethinking grammaticalization: New perspectives, 265-288. Amsterdam: John Benjamins.

Slade, Benjamin. 2011. Formal and philological inquiries into the nature of interrogatives, indefinites, disjunction, and focus in Sinhala and other languages. University of Illinois at Urbana-Champaign dissertation. https: //hdl.handle.net/2142/26068.

Slade, Benjamin. 2018. History of focus-concord constructions and focusassociated particles in Sinhala, with comparison to Dravidian and Japanese. Glossa 3(2). 1-28. https://doi.org/10.5334/gjgl.241.

Soe, Myint. 1999. A grammar of Burmese. Eugene, OR: University of Oregon dissertation.

Velleman, Leah, David Ian Beaver, Emilie Destruel, Dylan Bumford, Edgar Onea \& Liz Coppock. 2012. It-clefts are IT (Inquiry Terminating) constructions. Semantics and Linguistic Theory (SALT) 22. 441-46o. https://doi.o rg/10.3765/salt.v22io.2640.

Watanabe, Akira. 2002. Loss of overt wh-movement in Old Japanese. In David Lightfoot (ed.), Syntactic effects of morphological change, 179-195. Oxford: Oxford University Press.

Watkins, Justin (ed.). 2005. Studies in Burmese linguistics. Pacific Linguistics. https://doi.org/10.15144/PL-570.

Whitman, John. 1997. Kakarimusubi from a comparative perspective. Japanese/Korean Linguistics 6. 161-178.

Yanagida, Yuko. 2006. Word order and clause structure in early Old Japanese. Journal of East Asian Linguistics 15(1). 37-67. https://doi.org/10.1007/s1 0831-005-2165-2.

Yap, Foong Ha \& Karen Grunow-Hårsta. 2010. Non-referential uses of nominalization constructions: Asian perspectives. Language and Linguistics Compass 4(12). 1154-1175. https://doi.org/10.1111/j.1749-818X.2010.002 50.x. 
Michael Yoshitaka Erlewine

Dept. of English Language \& Literature National University of Singapore

7 Arts Link, Block AS5

Singapore 117570

mitcho@nus.edu.sg
Keely New

Dept. of English Language \& Literature

National University of Singapore

7 Arts Link, Block AS5

Singapore 117570

keely@u.nus.edu 